\title{
RESÍDUOS DE MEDICAMENTOS VETERINÁRIOS EM LEITE E OVOS
}

Érica Pacheco-Silva a Jurandir Rodrigues de Souza ${ }^{a}$ e Eloisa Dutra Caldas*,b

anstituto de Química, Universidade de Brasília, Campus Universitário Darcy Ribeiro, 70910-900 Brasília - DF, Brasil

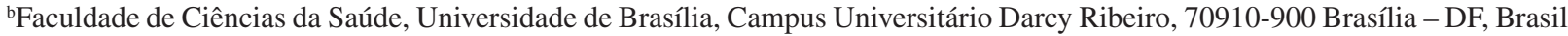

Recebido em 15/04/2013; aceito em 29/07/2013; publicado na web em 10/09/2013

\begin{abstract}
VETERINARY DRUG RESIDUES IN MILK AND EGGS. The use of veterinary drugs in food producing animals may result in the presence of residues in foods, including milk and eggs. Immunoassay or microbiological tests are used to screen for residues, but chromatographic methods are needed to confirm positive results. In most methods, the sample is extracted with acetonitrile, submitted to clean up or directly analyzed by LC-MS/MS. Results of the Brazilian governmental monitoring programs from 2006 to 2011 have shown that the antiparasitic ivermectin was the drug most frequently found in milk. Residues in eggs are only monitored by one of the programs, and few studies have reported the incidence of veterinary drugs in this matrix in Brazil.
\end{abstract}

Keywords: veterinary drugs; milk; eggs.

\section{INTRODUÇÃO}

Medicamentos são usados na medicina veterinária no tratamento e prevenção de doenças ou como promotores de crescimento. ${ }^{1,2}$ Estes compostos compreendem uma variedade de classes químicas com ações terapêuticas diversas, incluindo antibiótica/antimicrobiana, antiparasitária, inseticida, fungicida e sedativa. ${ }^{3}$ Os antimicrobianos ( $\beta$-lactâmicos, aminoglicosídeos e tetraciclinas) e os antiparasitários (avermectinas, piretróides e organofosforados) são os produtos mais comercializados no Paraná para tratamento do rebanho leiteiro. ${ }^{4}$

$\mathrm{O}$ uso de medicamentos veterinários em animais produtores de alimentos pode deixar resíduos nos alimentos, como carne, leite e ovos, cujos níveis não devem ultrapassar o Limite Máximo de Resíduos (LMR). O LMR é a concentração máxima de resíduo em um alimento de origem animal resultante do uso de um medicamento veterinário (expresso em $\mathrm{mg} / \mathrm{kg}$ ou $\mu \mathrm{g} / \mathrm{kg}$, em peso fresco) que é recomendado para ser legalmente permitido ou reconhecido como sendo aceitável no alimento. ${ }^{5}$ Estes limites são estabelecidos para garantir o uso adequado destes produtos, limitar a exposição e proteger a saúde dos consumidores dos alimentos provenientes de animais tratados. 5 A presença de resíduos em um alimento acima do LMR estabelecido indica que o produto não foi utilizado segundo as boas práticas de uso de medicamentos veterinários (BPMV), ou o uso de um produto não autorizado. ${ }^{6} \mathrm{O}$ Brasil não estabelece LMR para medicamentos veterinários, adotando aqueles recomendados pelo Mercosul, Codex Alimentarius, União Européia ou Estados Unidos. ${ }^{7}$

A exposição humana a resíduos de medicamentos veterinários presentes nos alimentos pode causar efeitos adversos, incluindo reações alérgicas em indivíduos hipersensíveis ${ }^{8}$ e câncer. ${ }^{9,10}$ Adicionalmente, a exposição a antimicrobianos/antibióticos pode provocar o desenvolvimento de microrganismos resistentes, que dificulta a ação terapêutica destes medicamentos em indivíduos que consumiram alimentos de animais tratados. ${ }^{11,12}$ Resíduos de medicamentos veterinários no leite podem também causar problemas tecnológicos nos processos de fermentação dos laticínios. ${ }^{13,14}$

No Brasil, há dois programas nacionais que monitoram a presença de resíduos de medicamentos veterinários em produtos de origem animal. O Plano Nacional de Controle de Resíduos e Contaminantes (PNCRC) é coordenado pelo Ministério da Agricultura, Pecuária e

*e-mail: eloisa@unb.br
Abastecimento (MAPA) e inclui programas setoriais para análise de carne, leite, ovos, mel e pescado. O Programa de Análise de Resíduos de Medicamentos Veterinários em Alimentos (PAMVet), da Agência Nacional de Vigilância Sanitária (ANVISA), analisa leite UHT, leite em pó e leite pasteurizado.

Recentemente, estudos foram publicados reportando dados relativos a resíduos de medicamentos veterinários no âmbito do PNCRC em produtos cárneos, ${ }^{15-19}$ peixe, ${ }^{20} \mathrm{mel}^{20,21}$ e leite. ${ }^{18,22} \mathrm{~A}$ presente revisão tem como foco os resíduos de medicamentos veterinários em leite e ovos, alimentos de grande importância para o mercado interno e consumidor brasileiro.

\section{MEDICAMENTOS VETERINÁRIOS}

Atualmente no Brasil existem 6.674 produtos de uso veterinário com registro vigente no MAPA. ${ }^{23,24}$ Dentre estes produtos, $607(9,1 \%)$ são antimicrobianos, antibióticos e antiparasitários com uso autorizado em bovinos, suínos, caprinos, ovinos e/ou aves e cuja presença de seus resíduos tem sido monitorada. ${ }^{23,24}$ Dentre estes medicamentos monitorados, as classes que apresentam o maior número de produtos registrados são avermectinas $(26,0 \%)$, $\beta$-lactâmicos $(15,0 \%)$, aminoglicosídeos $(14,5 \%)$, tetraciclinas $(13,2 \%)$ e sulfonamidas $(8,2 \%)$.

\section{Antibióticos e antimicrobianos}

Antibióticos e antimicrobianos (Quadro 1) são medicamentos que possuem ação bactericida e/ou bacteriostática por meio de diferentes mecanismos. Enquanto os compostos antibióticos são obtidos naturalmente ou por via semi-sintética, os antimicrobianos são compostos sintetizados quimicamente..$^{25}$

Os antibióticos são frequentemente utilizados no tratamento da mastite, pneumonia, diarréia e artrite em animais produtores de alimentos. ${ }^{26}$ Os $\beta$-lactâmicos, como as penicilinas, inibem a transpeptidase bacteriana mediante uma ligação covalente, impedindo a formação da parede celular. ${ }^{7}$ A estrutura das penicilinas (como a penicilina $\mathrm{G}$ ) consiste de um anel $\beta$-lactâmico ligado a um anel de cinco membros contendo tiazolidina.

As tetraciclinas são caracterizadas pela estrutura de quatro anéis parcialmente conjugados e o grupo funcional carboxiamido..$^{27,28}$ e são utilizadas para controlar infecções bacterianas. $\mathrm{O}$ uso de anfenicóis, tetraciclinas, $\beta$-lactâmicos (benzilpenicilâmicos e cefalosporinas), 
quinolonas e sulfonamidas sistêmicas como aditivos melhoradores de desempenho ou como conservantes alimentares é proibido no Brasil (Instrução normativa $\mathrm{N}^{\circ} 26$, de 9 de julho de 2009). ${ }^{29}$

Quadro 1.Exemplos de medicamentos veterinários (classe) e suas estruturas químicas

Penicilina G ( $\beta$-lactâmicos)

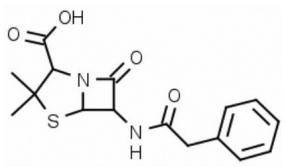

Eritromicina (Macrolídeos)

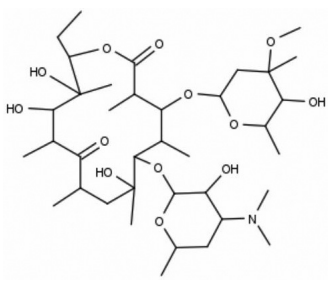

Cloranfenicol (Anfenicol)<smiles>O=C(NC(CO)C(O)c1ccc([N+](=O)[O-])cc1)C(Cl)Cl</smiles>

Nitrofurantoína(AHD) (Metabólito de nitrofurano)<smiles>NN1CC(=O)NC1=O</smiles>



Os macrolídeos, utilizados principalmente no tratamento de doenças respiratórias, ${ }^{30}$ são moléculas com uma lactona central ligada a um ou vários grupos desoxi-glicóis. A eritromicina é um antibiótico desse grupo, cujo mecanismo de ação consiste na inibição da síntese protéica pela ligação à porção $50 \mathrm{~S}$ dos ribossomos bacterianos. ${ }^{7,18} \mathrm{Os}$ aminoglicosídeos, como a estreptomicina, são antibióticos de amplo espectro, utilizados principalmente contra bactérias gram-negativas, atuando também na inibição da síntese protéica. ${ }^{31}$

O cloranfenicol é um antibiótico de amplo espectro da classe dos anfenicóis, com atividade contra bactérias gram-positivas e gram-negativas e outros grupos de microrganismos. ${ }^{32} \mathrm{O}$ seu uso foi proibido em muitos países, inclusive no Brasil, devido aos efeitos tóxicos graves relatados em humanos, como anemia aplástica e carcinogenicidade, ainda que presente em baixos níveis de concentração. ${ }^{33,34}$ Resíduos de cloranfenicol têm sido detectados em produtos de origem animal no país, indicando o seu uso ilegal. ${ }^{7}$
As sulfonamidas, nitrofuranos e quinolonas são exemplos de agentes antimicrobianos. ${ }^{25}$ As sulfonamidas são medicamentos de baixo custo, utilizados no tratamento de infecções bacterianas com amplo espectro de atuação. Elas competem com o ácido $p$-aminobenzóico, impedindo a sua utilização pelos microrganismos na síntese do ácido fólico, essencial para a síntese de ácidos nucléicos. ${ }^{35}$

Os nitrofuranos são utilizados no tratamento de infecções gastrointestinais e dermatológicas, além do tratamento da salmonelose. ${ }^{27}$ A carcinogenicidade e mutagenicidade desses compostos e de seus metabólitos levaram à proibição de sua utilização em animais produtores de alimentos em diversos países ${ }^{36,37}$ inclusive no Brasil. ${ }^{34}$ Após sua aplicação, os nitrofuranos são rapidamente metabolizados, tornando impossível a detecção do princípio ativo, porém foi observado o acúmulo de seus metabólitos ligados a proteínas. Estes metabólitos são estáveis e podem persistir no animal por várias semanas após a administração do nitrofurano equivalente. ${ }^{37}$

As quinolonas e fluoroquinolonas são derivados do ácido nalidixico inibidores da enzima DNA topoisomerase II (girase de DNA), importante na desnovelação do DNA, afetando a divisão celular da bactéria. As fluoroquinolonas mais recentes têm maior espectro de atividade, sendo em geral muito ativas contra patógenos aeróbios gram-negativos e de ação intermediária contra cocos gram-positivos. ${ }^{38}$

\section{Antiparasitários}

As avermectinas e os benzimidazóis são os medicamentos veterinários mais usados na pecuária atualmente para tratamento de um amplo espectro de doenças parasíticas. ${ }^{39}$ As avermectinas pertencem à classe das lactonas macrocíclicas (Quadro 1) e são utilizadas no tratamento de infecções causadas por endo e ectoparasitas. Apresentam caráter lipofílico e são monitoradas no tecido adiposo e fígado. É contra-indicado o uso de ivermectina e doramectina em bovinos produtores de leite para consumo humano, entretanto, estes medicamentos têm sido encontrados em amostras de leite. ${ }^{7,40}$ Produtos veterinários contendo ivermectina representam $65,2 \%$ de todas as avermectinas registradas no Brasil, principalmente devido a sua maior eficiência na eliminação dos parasitas e sua persistência no animal, o que pode acarretar na presença de resíduos nos alimentos de origem animal, inclusive acima do $\mathrm{LMR}^{41}$

Os benzimidazóis são medicamentos veterinários com ação anti-helmíntica por meio da inibição da formação de microtúbulos do parasito, importantes na formação do fuso mitótico, motilidade e secreção celular, absorção de nutrientes e transporte celular. ${ }^{42} \mathrm{~A}$ estrutura dos benzimidazóis é caracterizada por um anel benzênico condensado a um grupo imidazol (Quadro 1).

\section{MÉTODOS ANALÍTICOS PARA ANÁLISE DE RESÍDUOS DE MEDICAMENTOS VETERINÁRIOS}

Os baixos LMR estabelecidos pelos órgãos internacionais e de regulação para medicamento veterinário em produtos de origem animal, o uso ilegal de algumas substâncias e a complexidade das matrizes requerem o desenvolvimento de metodologias analíticas sensíveis, seletivas e robustas. Vários métodos têm sido utilizados no monitoramento de resíduos de medicamentos veterinários em alimentos de origem animal. Estes métodos podem ser divididos em dois grandes grupos: métodos biológicos de triagem e métodos cromatográficos.

\section{Métodos biológicos de triagem}

Métodos biológicos de triagem têm sido largamente utilizados na investigação da presença de resíduos de medicamentos veterinários em várias matrizes, principalmente devido à simplicidade 
na execução, rapidez e, geralmente, baixo custo. ${ }^{43}$ Estes métodos qualitativos ou semiquantitativos são baseados, principalmente, em técnicas imunológicas e microbiológicas. Entre as técnicas imunológicas, as mais comuns são o ELISA (do inglês enzyme-linked immuno sorbent assay), o radioimunoensaio (RIA) e biosensores. No ELISA, a atividade enzimática resultante da reação enzima-anticorpo-antígeno causa uma variação de cor que pode ser medida por técnicas colorimétricas. ${ }^{44}$ O RIA permite a medida da radioatividade de um complexo imunológico usando um contador. Na técnica com biosensores, em expansão na área de alimentos nos últimos anos, o analito entra em contato com um anticorpo e o sinal bioquímico é convertido num sinal elétrico. ${ }^{43}$ As técnicas microbiológicas baseiam-se na inibição do crescimento de microrganismos no meio onde pode estar presente o antibiótico ou antimicrobiano. ${ }^{45}$ Estas análises são feitas normalmente com kits comerciais, tais como o SNAP® Tetracycline e Ridascreen ${ }^{\circledast}$ chloramphenicol para ensaios imunológicos por ELISA ${ }^{46}$ e o FAST ${ }^{\circledR}$ (Antimicrobial Screening Test) and Premi ${ }^{\circledR}$ Test para testes microbiológicos. ${ }^{47}$

Os métodos de triagem devem ser capazes de detectar um analito ou uma classe de substâncias no nível de interesse ( $\geq$ LMR), porém alguns são pouco seletivos ${ }^{2,48}$ e podem fornecer resultados falso-positivos, sendo necessária a confirmação de amostras positivas por métodos cromatográficos, ${ }^{49,50}$ que serão discutidas a seguir.

\section{Métodos cromatográficos confirmatórios e multirresíduos}

A análise de medicamentos veterinários tem sido feita principalmente por cromatografia líquida de alta eficiência (High Performance Liquid Chromatography - HPLC) utilizando detector ultravioleta/ visível (UV/Vis) ou fluorescência (FL), e mais recentemente, acoplado à espectrometria de massas (MS ou MS/MS). A espectrometria de massas possibilita identificar e quantificar qualquer componente ionizável, elucidar estrutura e determinar sua massa molar. ${ }^{51} \mathrm{~A}$ cromatografia líquida acoplada à espectrometria de massas (LC-MS ou LC-MS/MS) é a técnica analítica mais utilizada para detecção e quantificação de resíduos, devido a sua alta sensibilidade e seletividade,${ }^{51}$ apresentando limite de quantificação (LOQ) na ordem de ng/ $\mathrm{mL}$ (ou $\mu \mathrm{g} / \mathrm{kg}$ ) para a maioria dos compostos (Tabela 1).

A grande variedade de medicamentos veterinários utilizada na produção animal pode levar à presença de vários resíduos nas matrizes de alimentos para consumo humano. Desta maneira, o desenvolvimento de métodos multirresíduos para análise de resíduos em alimentos tem se tornado cada vez mais importante. O preparo de amostra pode ser a etapa mais laboriosa de um método multirresíduo, e diferentes estratégias têm sido utilizadas para extrair os resíduos e realizar o clean-up da amostra. ${ }^{52}$ As técnicas mais empregadas para matrizes de origem animal são a extração líquido-líquido (ELL), ${ }^{22}$ extração em fase sólida (EFS), ${ }^{53}$ extração em fase sólida dispersiva (EFSdispersivo), ${ }^{18}$ dispersão de matriz em fase sólida (DMFS),${ }^{31}$ extração líquido-líquido com purificação em baixa temperatura (ELL-PBT), ${ }^{54,55}$ extração líquido-líquido com rápida partição à baixa temperatura (ELL-RPBT), ${ }^{56,57}$ e o método QuEChERS (do inglês Quick, Easy, Cheap, Effective, Rugged and Safe)..$^{58}$

A Tabela 1 mostra alguns trabalhos publicados nos últimos anos na análise de resíduos de medicamentos veterinários em amostras de leite, ovos e outras matrizes. Observa-se que a ELL é o método de extração mais empregado, principalmente utilizando acetonitrila como solvente, seguido ou não pela etapa de clean-up utilizando EFS, principalmente com coluna Oasis HLB e C18. A ELL-PBT, utilizada por alguns autores, foi desenvolvida principalmente para simplificar a etapa de clean up de matrizes gordurosas e permitir a quantificação multirresíduos por cromatografia. ${ }^{89}$ Nesse método, a amostra líquida ou sólida é misturada à acetonitrila e, após agitação, levada ao freezer por um período mínimo de seis horas. Nesta etapa, a fase aquosa juntamente com a amostra é separada do solvente e os analitos extraídos são filtrados com sulfato de sódio anidro e o extrato diretamente injetado no cromatógrafo. ${ }^{55} \mathrm{~A}$ técnica ELL-PBT apresenta como vantagem a simplicidade e eficiência, além do menor consumo de solventes, a ausência de outras etapas de clean up e a redução ou eliminação de etapas de evaporação e troca de solventes. Na ELL-RPBT, o nitrogênio líquido é utilizado para o congelamento da fase água/acetonitrila, tornando o processo mais rápido. ${ }^{56,57}$ Trabalhos mais recentes têm usado o método QuEChERS e suas modificações para extração de antibióticos e clean-up em matrizes de origem animal. ${ }^{14,88,90-93}$ No método original, a acetonitrila é utilizada para extração dos analitos e precipitação das proteínas, com remoção da água e separação de fases por salting out com sulfato de magnésio e cloreto de sódio. Posteriormente o extrato é submetido à etapa de clean up por EFS-dispersiva usando PSA (amina primária e secundária) e analisado diretamente por cromatografia gasosa ou líquida com detectores de massa. ${ }^{94} \mathrm{Na}$ análise de matrizes de origem animal tem sido adicionado ácido acético e $\mathrm{Na}_{2}$ EDTA à acetonitrila e substituído o cloreto de sódio por acetato de sódio. Após a etapa de centrifugação, os extratos são diluídos com metanol acidificado com ácido fórmico para análise direta por LC-MS/MS ${ }^{14,88}$ ou submetidos à etapa de clean-up utilizando sorventes $\mathrm{NH}_{2}$ ou PSA, ${ }^{81}$ ou $\mathrm{MgSO}_{4} \mathrm{e}$ C18 antes da análise. ${ }^{82}$

Valores de limite de decisão $(\mathrm{CC} \alpha)$ e capacidade de detecção (CC $\beta$ ) também são reportados em alguns estudos (Tabela 1). Estes valores são requeridos pelas agências reguladoras com o objetivo de medir o desempenho analítico (incerteza da medição) de um método num dado LMR a um determinado nível de confiança. ${ }^{95} \mathrm{CC} \alpha$ é definido como o menor nível de concentração no qual o método pode discriminar com uma certeza estatística de $95 \%$ a presença de um composto que apresenta LMR. CC $\beta$ representa a menor quantidade da substância que pode ser detectada, identificada e/ou quantificada em uma amostra com uma probabilidade de erro aceitável $(\beta=5 \%) .^{96,97}$ Em geral, o $\mathrm{CC} \alpha$ e $\mathrm{CC} \beta$, relacionados ao LMR, são maiores que o LOD e LOQ, os quais estão diretamente relacionados com a sensibilidade do método analítico. As recuperações obtidas para a maioria dos estudos mostrados na Tabela 1 estão dentro dos valores aceitos pelas agências nacionais e internacionais (50-120\%). ${ }^{95,98}$

\section{RESÍDUOS DE MEDICAMENTOS VETERINÁRIOS EM LEITE E OVOS}

\section{Programas de monitoramento de resíduos de medicamentos veterinários no Brasil}

De uma maneira geral, os princípios ativos escolhidos para serem monitorados nos programas governamentais do MAPA e da ANVISA são aqueles que podem deixar resíduos nos alimentos, podendo constituir barreiras às exportações dos produtos de origem animal e que possam representar risco potencial à saúde humana quando presentes no alimento. ${ }^{7}$

\section{PNCRC/MAPA}

O PNCRC para produtos de origem animal teve suas diretrizes instituídas pela Instrução Normativa do MAPA (IN) no 42 em $1999^{99}$ e o seu escopo criado para análise de resíduos e contaminantes químicos e biológicos em carne, leite, mel e pescado de forma a atender a demanda nacional e internacional. Em março de 2006, a União Européia decidiu suspender a importação de mel produzido no Brasil sob a alegação de que o País não teria equivalência com o bloco no que se referia às diretivas para controle de resíduos e qualidade do produto. ${ }^{100}$ Porém, já em 2005, o MAPA alterou seu escopo relativo a 
Tabela 1. Métodos de extração para determinação de drogas veterinárias em leite e ovos

\begin{tabular}{|c|c|c|c|c|c|c|c|}
\hline Medicamentos & $\begin{array}{c}\text { Matriz } \\
\text { relevante }\end{array}$ & Preparo da amostra & Análise & $\begin{array}{l}\mathrm{LOD} / \\
\mathrm{CC} \alpha\end{array}$ & $\begin{array}{l}\mathrm{LOQ} / \\
\mathrm{CC} \beta\end{array}$ & $\begin{array}{l}\text { Recuperação, } \\
\text { (RSD), \% }\end{array}$ & Ref. \\
\hline Avermectinas & $\begin{array}{l}\text { Leite, ovos e } \\
\quad \text { carne }\end{array}$ & $\begin{array}{l}\text { ELL com MeOH } \rightarrow \text { partição com hexano } \\
\rightarrow \text { derivatização com metil-imidazol }\end{array}$ & HPLC-FL & $\begin{array}{c}\mathrm{NR} / \\
2,1-119 \\
\mu \mathrm{g} / \mathrm{kg}\end{array}$ & $\begin{array}{c}5 / \\
2,9-138 \\
\mu \mathrm{g} / \mathrm{kg}\end{array}$ & $\begin{array}{l}60-90 \\
(<17,4)\end{array}$ & 59 \\
\hline Cloranfenicol & $\begin{array}{l}\text { Leite, ovos e } \\
\text { tecido }\end{array}$ & $\begin{array}{c}\text { ELL com } \mathrm{MeCN} \text { e } \mathrm{NaCl} \rightarrow \\
\text { partição em hexano }\end{array}$ & LC-MS & $\begin{array}{r}0,2-0,6 \\
\mathrm{ng} / \mathrm{g} / \mathrm{NR}\end{array}$ & NR & $\begin{array}{c}83-109 \\
(<17)\end{array}$ & 60 \\
\hline $\begin{array}{c}\text { Sulfonamidas, } \\
\text { tetraciclinas, e } \\
\text { pirimetamina } \\
\end{array}$ & Leite & $\begin{array}{c}\text { ELL com ácido tricloroacético e tampão } \\
\text { de Mcllvaine } \rightarrow \mathrm{pH} 4,5 \rightarrow \\
\text { EFS (Oasis }{ }^{\oplus} \text { HLB) } \\
\end{array}$ & LC-MS & NR & NR & $70-106$ & 61 \\
\hline $\begin{array}{c}\text { Sulfonamidas, } \\
\text { tetraciclinas, e } \\
\text { pirimetamina }\end{array}$ & Leite & $\begin{array}{c}\text { ELL com TCA e tampão de Mcllvaine } \rightarrow \\
\text { ajuste de pH para } 4,5 \rightarrow \\
\text { EFS }\left(\text { Oasis }^{\circledast} \text { HLB) }\right. \\
\end{array}$ & LC-MS & $\begin{array}{l}0,51-2,64 / \\
\mathrm{NR} n g / \mathrm{mL}\end{array}$ & $\begin{array}{l}0,97-8,64 / \\
\text { NR ng/mL }\end{array}$ & $\begin{array}{l}72-97 \\
(<11)\end{array}$ & 62 \\
\hline Avermectinas & Leite & $\begin{array}{l}\text { ELL com } \mathrm{MeCN} \text { e } \mathrm{NaCl} \rightarrow \\
\text { congelamento }\left(-20^{\circ} \mathrm{C}, 12 \mathrm{~h}\right)\end{array}$ & $\begin{array}{l}\text { HPLC-FL e } \\
\text { LC-MS/MS }\end{array}$ & $\begin{array}{c}0,4-5,8 / \\
10,4-25,7 \\
\mathrm{ng} / \mathrm{mL}\end{array}$ & $\begin{array}{c}1,2-14,2 / \\
11,0-38,3 \\
\mathrm{ng} / \mathrm{mL}\end{array}$ & $\begin{array}{l}100-105 \\
(<8,8) \\
101-142 \\
(<20) \\
\end{array}$ & 54 \\
\hline $\begin{array}{c}\text { Ionóforos poliéteres } \\
\text {, macrolídeos e } \\
\text { lincosamidas } \\
\end{array}$ & Ovos & ELL com $\mathrm{MeCN}$ & LC-MS/MS & $\begin{array}{l}0,04-1,6 / \\
0,87-230 \\
\mu \mathrm{g} / \mathrm{kg}\end{array}$ & $\begin{array}{c}0,14-5,3 / \\
1,74-263 \mu \mathrm{g} / \mathrm{kg}\end{array}$ & $\begin{array}{l}78-168,1 \\
\quad(<20)\end{array}$ & 63 \\
\hline Tetraciclinas & Leite & $\begin{array}{c}\text { ELL com EDTA }(0.1 \mathrm{~mol} / \mathrm{L}) \\
\text { em tampão McIlvaine pH } 4.0 \rightarrow \\
\text { EFS }\left(\text { Oasis }^{\circledR} \text { HLB }\right) \\
\end{array}$ & HPLC-FL & $\begin{array}{c}5,1-34,7 / \\
108-124 \\
\mu \mathrm{g} / \mathrm{kg} \\
\end{array}$ & $\begin{array}{c}50 / \\
117-161 \\
\mu \mathrm{g} / \mathrm{kg} \\
\end{array}$ & $\begin{array}{c}68-110 \\
(<13)\end{array}$ & 64 \\
\hline $\begin{array}{l}\text { Tetraciclinas e seus } \\
\text { 4-epímeros }\end{array}$ & Leite & $\begin{array}{l}\text { ELL com ácido oxálico }(0.01 \mathrm{~mol} / \mathrm{L}) \text { em } \\
\qquad \mathrm{MeCN} \rightarrow \text { EFS }\left(\mathrm{Oasis}^{\circledR} \mathrm{HLB}\right)\end{array}$ & LC-MS/MS & $\begin{array}{c}0.28-3.7 \\
\mu \mathrm{g} / \mathrm{L} / \\
\mathrm{LMR}+13.5 \% \\
\end{array}$ & $\begin{array}{l}0.95-12.2 \mu \mathrm{g} / \mathrm{L} / \\
\mathrm{LMR}+26.2 \%\end{array}$ & $>88,6$ & 53 \\
\hline $\begin{array}{l}\text { Anti-inflamatórios } \\
\text { não esteroidais }\end{array}$ & Leite & $\begin{array}{c}\text { ELL com MeCN } \rightarrow \text { re-extração com } \\
\text { MeCN, ácido ascórbico e } \mathrm{HCl} \rightarrow \\
\left.\text { pH=3 } \rightarrow \text { EFS (Evolute }{ }^{\mathrm{TM}} \mathrm{ABN}\right)\end{array}$ & LC-MS/MS & $\begin{array}{c}\mathrm{NR} / \\
0,46-2,86 \\
\mathrm{ng} / \mathrm{mL} \\
\end{array}$ & $\begin{array}{c}\mathrm{NR} / \\
0,79-4,87 \\
\mathrm{ng} / \mathrm{mL} \\
\end{array}$ & $\begin{array}{c}90-100 \\
(<20)\end{array}$ & 65 \\
\hline Aminoglicosídeo & Leite & $\begin{array}{c}\text { DMFS utilizando sílica tratada com } \\
\text { EDTA }\end{array}$ & LC-MS/MS & $1-6 \mathrm{ng} / \mathrm{mL}$ & $2-13 \mathrm{ng} / \mathrm{mL}$ & $\begin{array}{l}72-101 \\
(<15)\end{array}$ & 31 \\
\hline Antibióticos & Leite & ELL com MeCN $\rightarrow$ filtração. & LC-MS-Q-TOF & $\begin{array}{l}0,5-20 \mathrm{ng} / \mathrm{mL} / \\
\mathrm{NR}\end{array}$ & $\begin{array}{c}2-50 \mathrm{ng} / \mathrm{mL} / \\
\mathrm{NR}\end{array}$ & $\begin{array}{c}42-154 \\
(<33)\end{array}$ & 66 \\
\hline Antibióticos & Leite & $\begin{array}{l}\text { ELL com MeCN } \rightarrow \text { injeção do extrato } \\
\text { reconstituição com acetonitrila } 50 \% \text {. }\end{array}$ & LC-MS/MS & $\begin{array}{l}0,1-2,5 \\
\mathrm{ng} / \mathrm{mL} / \\
\mathrm{NR} \\
\end{array}$ & $\begin{array}{l}0,25-5 \\
\mathrm{ng} / \mathrm{mL} / \\
\mathrm{NR} \\
\end{array}$ & $\begin{array}{l}52-119,5 \\
\quad(<20)\end{array}$ & 67 \\
\hline Multi-classes & Leite & ELL com $\mathrm{MeCN}$ & LC-TOF & $\begin{array}{c}0,5-25 \\
\mu \mathrm{g} / \mathrm{L} / \\
0,2-159 \mu \mathrm{g} / \mathrm{L} \\
\end{array}$ & $\begin{array}{c}\mathrm{NR} / \\
1,0-100 \\
\mu \mathrm{g} / \mathrm{L} \\
\end{array}$ & $\begin{array}{l}3,0-809,0 \\
(<120)\end{array}$ & 50 \\
\hline Avermectinas & Leite & $\begin{array}{c}\text { ELL com MeCN e tampão Tris } \mathrm{pH}=8 \rightarrow \\
\text { EFS (Varian Bond Elut }{ }^{\circledR} \text { ) }\end{array}$ & LC-MS/MS & $\begin{array}{c}0,06-0,32 / \\
0,13-0,47 \\
\mu \mathrm{g} / \mathrm{L}\end{array}$ & $\begin{array}{c}0,18-0,93 / \\
0,26-0,94 \\
\mu \mathrm{g} / \mathrm{L} \\
\end{array}$ & $93-111(<22)$ & 40 \\
\hline Nitroimidazol & $\begin{array}{l}\text { Leite, ovos e } \\
\quad \text { outros }\end{array}$ & ELL com MeCN $\rightarrow$ EFS $\left(\right.$ Strata $^{\oplus}$-SDB $)$ & LC-MS/MS & $\begin{array}{c}0,05-0,10 / \\
0,05-0,10 \mu \mathrm{g} / \mathrm{kg}\end{array}$ & $\begin{array}{c}0,17-0,33 / \\
0,08-0,15 \\
\mu \mathrm{g} / \mathrm{kg} \\
\end{array}$ & $\begin{array}{l}56-110 \\
(<26,8)\end{array}$ & 68 \\
\hline Cloranfenicol & Leite e mel & $\begin{array}{l}\text { ELL com MeCN e clofórmio } \rightarrow \text { EFS } \\
\text { (copolímero estireno divinilbenzeno) }\end{array}$ & LC-MS/MS & $\begin{array}{c}0,52 \\
\mathrm{ng} / \mathrm{L} / \\
\mathrm{NR}\end{array}$ & $\begin{array}{c}1,85 \\
\mathrm{ng} / \mathrm{L} / \\
\mathrm{NR}\end{array}$ & $\sim 100(<8,41)$ & 69 \\
\hline Multi-classes & Leite & $\begin{array}{l}\text { ELL com ácido acético, } \mathrm{MeCN} \text {, } \\
\mathrm{Na}_{2} \text { EDTA, } \mathrm{MgSO}_{4} \text { e acetato de sódio }\end{array}$ & UPLC-MS/MS & $\begin{array}{c}1,0-4,0 \mu \mathrm{g} / \mathrm{kg} / \\
\mathrm{NR}\end{array}$ & $\begin{array}{c}3,0-10,0 \\
\mu \mathrm{g} / \mathrm{kg} / \\
\mathrm{NR}\end{array}$ & $\begin{array}{l}70-110 \\
(<20,4)\end{array}$ & 14 \\
\hline Multi-classes & $\begin{array}{l}\text { Leite e leite } \\
\text { em pó }\end{array}$ & $\begin{array}{c}\text { ELL com ácido acético, } \mathrm{MeCN}, \\
\mathrm{Na}_{2} \text { EDTA, } \mathrm{MgSO}_{4} \text { e acetato de sódio }\end{array}$ & $\begin{array}{l}\text { UPLC-Orbitrap- } \\
\text { MS }\end{array}$ & $\begin{array}{c}\mathrm{NR} / \\
6,1-213 \\
\mu \mathrm{g} / \mathrm{kg} \\
\end{array}$ & $\begin{array}{l}0,2-25 / \\
9,3-226 \\
\mu \mathrm{g} / \mathrm{kg}\end{array}$ & $\begin{array}{l}\text { NR } \\
(<20)\end{array}$ & 70 \\
\hline Multi-classes & $\begin{array}{l}\text { Ovo, peixe e } \\
\text { carne }\end{array}$ & $\begin{array}{c}\text { ELL com MeCN:H2O }(6: 4, \mathrm{v} / \mathrm{v}) \rightarrow \\
\text { EFS }\left(\text { StrataX }^{\oplus}\right)\end{array}$ & LC-ToF-MS & NR & $\begin{array}{l}\mathrm{NR} / \\
1,9-2119 \\
\mu \mathrm{g} / \mathrm{kg}\end{array}$ & $\begin{array}{l}70-90 \\
(8-15)\end{array}$ & 71 \\
\hline Multi-classes & Leite & $\begin{array}{c}\text { ELL com } \mathrm{Na}_{2} \text { EDTA e MeOH:MeCN (1:5) } \\
\rightarrow \text { ELL do sobrenadante com } \\
\text { etanol e MeCN }\end{array}$ & UPLC-MS/MS & NR & $\begin{array}{l}0,5-10 \\
\mu \mathrm{g} / \mathrm{kg} /\end{array}$ & $\begin{array}{c}63-141 \\
(<29)\end{array}$ & 72 \\
\hline $\begin{array}{l}\text { Anti-inflamatórios } \\
\text { não esteroidais e } \\
\text { corticóides }\end{array}$ & Leite & $\begin{array}{c}\text { ELL com } \mathrm{MeCN} \text { e } \mathrm{NaCl} \rightarrow \text { partição } \\
\text { com n-hexano }\end{array}$ & LC-MS/MS & $\begin{array}{c}\mathrm{NR} / \\
0,33-61,4 \\
\mu \mathrm{g} / \mathrm{kg} \\
\end{array}$ & $\begin{array}{c}\mathrm{NR} / \\
0,36-72,8 \mu \mathrm{g} / \mathrm{kg}\end{array}$ & $\begin{array}{c}\sim 100 \\
(<21,9)\end{array}$ & 73 \\
\hline Cloranfenicol & Leite & $\begin{array}{c}\text { ELL com acetato de etila e } \mathrm{Na}_{2} \mathrm{SO}_{4} \rightarrow \\
\text { partição com n-hexano }\end{array}$ & LC-MS/MS & $\begin{array}{r}0,08 \\
\mu \mathrm{g} / \mathrm{kg}\end{array}$ & $\begin{array}{c}0,10 \\
\mu \mathrm{g} / \mathrm{kg}\end{array}$ & $\begin{array}{l}>90 \\
(<15) \\
\end{array}$ & 74 \\
\hline
\end{tabular}


Tabela 1. continuação

\begin{tabular}{|c|c|c|c|c|c|c|c|}
\hline Medicamentos & $\begin{array}{c}\text { Matriz } \\
\text { relevante }\end{array}$ & Preparo da amostra & Análise & $\begin{array}{l}\mathrm{LOD} / \\
\mathrm{CC} \alpha\end{array}$ & $\begin{array}{l}\mathrm{LOQ} / \\
\mathrm{CC} \beta\end{array}$ & $\begin{array}{l}\text { Recuperação, } \\
\text { (RSD), \% }\end{array}$ & Ref. \\
\hline $\begin{array}{l}\text { Benzimidazóis, } \\
\text { avermectinas e } \\
\text { fenilbutazona }\end{array}$ & $\begin{array}{l}\text { Leite e mús- } \\
\quad \text { culo }\end{array}$ & $\begin{array}{l}\text { ELL com MeCN, EDTA e } \\
\text { ácido ascórbico }\end{array}$ & $\begin{array}{l}\text { UPLC-Orbitrap- } \\
\text { HRMS* e MS- } \\
\text { MS** }\end{array}$ & $\begin{array}{c}\mathrm{NR} / \\
1,0-112^{*} \\
\mathrm{e} 1,1-113^{* *} \\
\mu \mathrm{g} / \mathrm{kg} \\
\end{array}$ & $\begin{array}{c}\mathrm{NR} / \\
1,1-148 * \text { e } 1,2- \\
147 * * \\
\mu \mathrm{g} / \mathrm{kg} \\
\end{array}$ & $\begin{array}{l}70-130 \\
(<50)\end{array}$ & 75 \\
\hline Quinolonas & Ovos & Extração líquida pressurizada. & HPLC-FL & NR & NR & $\begin{array}{l}60-100 \\
(17-30)\end{array}$ & 76 \\
\hline $\begin{array}{l}\text { Estreptomicina/ } \\
\text { diidroestrepto- } \\
\text { micina }\end{array}$ & Leite & $\begin{array}{l}\text { ELL com ácido tricloroacético }(2 \mathrm{x}) \rightarrow \\
\left.\text { a) EFS (DSC }{ }^{\circledast}-\mathrm{WCX}\right) \\
\text { b) EFS por HILIC }\left(\text { Oasis }^{\circledast} \text { WCX) }\right.\end{array}$ & LC-MS & NR & $\begin{array}{c}\text { a) } 109 \text { e } 31 \\
\text { b) } 13,9 \text { e } 14,0 \\
\mu \mathrm{g} / \mathrm{kg} / \\
\mathrm{NR}\end{array}$ & $\begin{array}{l}\text { a) } 69,3 \text { e } 56,5 \\
\text { b) } 85,5 \text { e } 72,3 \\
(<13)\end{array}$ & 77 \\
\hline Sulfonamidas & Leite & $\begin{array}{c}\text { Diluição } \rightarrow \text { extração com barra sorptiva } \\
\text { (polímero monolítico) } \rightarrow \text { eluição com } \\
\text { MeCN } \\
\end{array}$ & $\begin{array}{l}\text { HPLC- } \\
\text { DAD }\end{array}$ & $\begin{array}{c}1,29-7,9 / \mathrm{NR} \\
\mathrm{ng} / \mathrm{mL}\end{array}$ & $\begin{array}{c}4,29-26,3 / \mathrm{NR} \\
\mathrm{ng} / \mathrm{mL}\end{array}$ & $\begin{array}{c}54-126 \\
(<13)\end{array}$ & 78 \\
\hline $\begin{array}{l}\text { Lincomicina e } \\
\text { narasina }\end{array}$ & $\begin{array}{l}\text { Músculo, leite } \\
\text { e ovos }\end{array}$ & $\begin{array}{l}\text { Leite: ELL com tampão fosfato, } \mathrm{NaOH} \text { e } \\
\text { MeCN } \rightarrow \text { congelamento }\left(-20^{\circ} \mathrm{C}, 30 \mathrm{~min}\right) \\
\text { Ovo: ELL com } \mathrm{MeCN} \rightarrow \text { congelamento } \\
\left(-20^{\circ} \mathrm{C}, 30 \mathrm{~min}\right)\end{array}$ & LC-MS/MS & $\begin{array}{l}0,6-1,5 / \\
\mathrm{NR} \\
\mathrm{ng} / \mathrm{g}\end{array}$ & $\begin{array}{l}2-5 / \\
\mathrm{NR} \\
\mathrm{ng} / \mathrm{g}\end{array}$ & $\begin{array}{l}90-101 \text { e } \\
85-95 \\
(<14)\end{array}$ & 79 \\
\hline $\begin{array}{c}\text { Cloranfenicol, } \\
\text { enrofloxacina e } 29 \\
\text { pesticidas } \\
\end{array}$ & Leite & $\begin{array}{c}\text { ELL com } \mathrm{MeCN}, \mathrm{Na}_{2} \mathrm{SO} 4 \text { e } \mathrm{NaCl} \rightarrow \text { EFS } \\
(\mathrm{C} 18) .\end{array}$ & LC-MS/MS & $\begin{array}{c}0,01-4,8 \mu \mathrm{g} / \mathrm{kg} / \\
\mathrm{NR}\end{array}$ & $\begin{array}{c}0,03-14,5 \mu \mathrm{g} / \mathrm{kg} / \\
\mathrm{NR}\end{array}$ & $\begin{array}{c}71-107 \\
(13,7)\end{array}$ & 80 \\
\hline $\begin{array}{l}\begin{array}{l}\text { Quinolonas, sulfon- } \\
\text { amidas, }\end{array} \\
\text { Anti-helmínticos } \\
\end{array}$ & $\begin{array}{l}\text { Ovos, carne e } \\
\text { leite }\end{array}$ & $\begin{array}{l}\text { ELL com MeCN e Na2SO4 } \rightarrow \text { filtração } \\
\rightarrow \text { Lavagem com MeCN e ácido acético } \\
\quad \rightarrow \text { EFS }\left(\text { Bond Elut } \mathrm{SCX}^{\oplus} \text { ) }\right.\end{array}$ & LC-MS & NR & NR & $56-104(<15)$ & 81 \\
\hline Benzimidazol & Leite & QuEChERS $\rightarrow$ EFS-dispersivo com C18 & UPLC-MS/MS & $\begin{array}{c}2,7 \mu \mathrm{g} / \mathrm{kg} / \\
\mathrm{NR}\end{array}$ & $\begin{array}{c}\mathrm{NR} / \\
5 \mu \mathrm{g} / \mathrm{kg}\end{array}$ & $\begin{array}{c}81-116 \\
(<35)\end{array}$ & 82 \\
\hline $\begin{array}{l}\text { Tetraciclinas, } \\
\text { sulfonamidas e } \\
\text { cloranfenicol } \\
\end{array}$ & Leite & $\begin{array}{l}\text { ELL com TCA em MeOH e tampão de } \\
\text { Mcllvaine pH } 4 \rightarrow \text { EFS (OASIS HLB). }\end{array}$ & HPLC-DAD & $\begin{array}{c}20 \\
\mathrm{ng} / \mathrm{mL}\end{array}$ & $\begin{array}{c}60 \\
\mathrm{ng} / \mathrm{mL}\end{array}$ & $\begin{array}{c}83-112 \\
(<12)\end{array}$ & 83 \\
\hline $\begin{array}{l}\text { Nitroimidazóis e } \\
\text { seus metabólitos }\end{array}$ & $\begin{array}{l}\text { Ovo, carne e } \\
\text { peixe }\end{array}$ & ELL com $\mathrm{MeCN} \rightarrow$ EFS (SiOH) & LC-MS/MS & $\begin{array}{c}\mathrm{NR} / \\
0,13-1,0 \\
\mu \mathrm{g} / \mathrm{kg}\end{array}$ & $\begin{array}{c}\mathrm{NR} / \\
0,20-0,60 \\
\mu \mathrm{g} / \mathrm{kg} \\
\end{array}$ & $\begin{array}{l}88-98 \\
(<15)\end{array}$ & 84 \\
\hline Cloranfenicol & Leite em pó & $\begin{array}{c}\text { ELL com ácido tricloroacético } \rightarrow \mathrm{H}_{2} \mathrm{O} \rightarrow \\
\text { pH } 5 \rightarrow \text { a) EFS }\left(\text { Oasis }^{\oplus} \mathrm{HLB}\right) \\
\text { b) ELL } \\
\end{array}$ & LC-MS/MS & $\mathrm{NR} / 0,02 \mu \mathrm{g} / \mathrm{kg}$ & $\mathrm{NR} / 0,03 \mu \mathrm{g} / \mathrm{kg}$ & $\begin{array}{l}\sim 100 \\
(<20)\end{array}$ & 85 \\
\hline $\begin{array}{c}\text { Tetraciclina, } \\
\text { oxitetraciclina e } \\
\text { 4-epitetraciclina } \\
\end{array}$ & Leite & ELL com McIlvane/EDTA $\rightarrow$ EFS (C18) & HPLC-UV & NR & NR & $\begin{array}{l}71,5-91,5 \\
(<7)\end{array}$ & 86 \\
\hline Cloranfenicol & $\begin{array}{l}\text { Leite, ovos e } \\
\text { outros }\end{array}$ & $\begin{array}{l}\text { Diluição com } \mathrm{H} 2 \mathrm{O} \rightarrow \text { ELL com MeCN } \\
\rightarrow \text { partição com clorofórmio }\end{array}$ & LC-MS/MS & $\begin{array}{c}\mathrm{NR} / \\
0,002-0,035 \\
\mu \mathrm{g} / \mathrm{kg} \\
\end{array}$ & $\begin{array}{c}\mathrm{NR} / \\
0,04-0,057 \\
\mu \mathrm{g} / \mathrm{kg} \\
\end{array}$ & $\begin{array}{l}\mathrm{NR} \\
(<25)\end{array}$ & 87 \\
\hline $\begin{array}{l}\text { Antibióticos, } \\
\text { coccidiostáticos e } \\
\text { corticosteróides } \\
\end{array}$ & Leite & ELL com MeCN $\rightarrow$ EFS $\left(\right.$ Strata $\left.^{\mathrm{TM}}-\mathrm{X}\right)$ & LC-MS/MS & $\begin{array}{c}\mathrm{NR} / \\
0,1-18,7 \\
\mathrm{ng} / \mathrm{mL}\end{array}$ & $\begin{array}{c}\mathrm{NR} / \\
0,2-31,8 \\
\mathrm{ng} / \mathrm{mL}\end{array}$ & $\begin{array}{l}71-110 \\
(<22)\end{array}$ & 48 \\
\hline Multi-classes & Ovos & $\begin{array}{c}\text { ELL com MeCN, ácido cítrico e } \\
\mathrm{Na}_{2} \text { EDTA } \rightarrow \\
\text { EFS }\left(\text { Oasis }^{\oplus} \text { HLB }\right) \\
\end{array}$ & UPLC-MS/MS & $\begin{array}{c}\mathrm{NR} / \\
2,1-220,8 \\
\mu \mathrm{g} / \mathrm{kg}\end{array}$ & $\begin{array}{c}0,1-5,0 / \\
4,1-241,6 \\
\mu g / \mathrm{kg}\end{array}$ & $\begin{array}{l}57,1-120 \\
(<25,1)\end{array}$ & 88 \\
\hline $\begin{array}{l}\text { Cloranfenicol e } \\
\text { florfenicol }\end{array}$ & Leite e carne & $\begin{array}{c}\text { ELL com solução de ácido fórmico, } \\
\text { sulfato de sódio e acetato de etila } \rightarrow \\
\text { EFS-dispersivo (C18) }\end{array}$ & LC-MS/MS & $\begin{array}{c}0,066-1,65 / \\
0,13-12,8 \\
\mu \mathrm{g} / \mathrm{kg}\end{array}$ & $\begin{array}{c}0,22-5,4 / \\
0,21-18,3 \\
\mu \mathrm{g} / \mathrm{kg}\end{array}$ & $\begin{array}{c}89-107 \\
(4-15)\end{array}$ & 18 \\
\hline$\beta$-lactâmicos & Leite & ELL com $\mathrm{MeCN}$ e $\mathrm{NaCl}$ & LC-MS/MS & $\begin{array}{c}0,4-10 / \\
4,7-120 \\
\mathrm{ng} / \mathrm{mL} \\
\end{array}$ & $\begin{array}{c}1-25 / \\
5,7-148 \\
\mathrm{ng} / \mathrm{mL} \\
\end{array}$ & $\begin{array}{l}41,9-81,3 \\
\quad(<14)\end{array}$ & 22 \\
\hline
\end{tabular}

ELL = Extração líquido-líqudo; EFS = Extração em fase sólida; $\mathrm{MeOH}$ = metanol; $\mathrm{MeCN}$ = acetonitrila; Tampão de Mcllvaine é composto de ácido cítrico monohidratado, fosfato de sódio dibásico e $\mathrm{Na}_{2} \mathrm{EDTA}$ em água. Tris = tris-hidroximetilaminometano, $\mathrm{NR}=$ Não reportado; LMR = Limite máximo de resíduo; LOD = limite de detecção; LOQ = limite de quantificação; RSD = desvio padrão relativo.

medicamentos veterinários para atender as exigências da Comunidade Européia, que sugeriu que o Brasil aperfeiçoasse o programa de resíduos em mel, criasse um plano de resíduo em ovos, adicionasse os resíduos exigidos pela legislação européia e realizasse a confirmação dos dados qualitativos obtidos com métodos de triagem, entre outras solicitações. ${ }^{101} \mathrm{O}$ escopo analítico do programa foi readequado ao longo dos anos de acordo com o aumento da capacidade analítica dos laboratórios do MAPA. ${ }^{102}$ A Tabela 2 mostra os LMR dos medicamentos analisados atualmente no PNCRC e PAMVet.

As amostras monitoradas pelo PNCRC são coletadas de acordo com o plano de amostragem recomendado pelo comitê do Codex Alimentarius, e o MAPA publica anualmente no Diário Oficial da União o número de amostras previstas para serem analisadas no programa. ${ }^{103,104}$ As amostras são coletadas por fiscais federais 
Tabela 2. Limite Máximo de Resíduos (LMR) e escopo atual do PNCRC e PAMVet para drogas veterinárias em leite e ovos

\begin{tabular}{|c|c|c|c|c|c|}
\hline \multirow[t]{2}{*}{ Medicamentos veterinários } & & \multicolumn{2}{|c|}{$\begin{array}{c}\text { LMR, } \\
\mu \mathrm{g} / \mathrm{L} \text { ou } \mu \mathrm{g} / \mathrm{kg}\end{array}$} & \multicolumn{2}{|c|}{ Programa } \\
\hline \multirow{2}{*}{\multicolumn{6}{|c|}{ Antibióticos/antimicrobianos }} \\
\hline & & & & & \\
\hline \multirow{12}{*}{$\beta$-lactâmicos } & Ceftiofur & 100 & - & $\mathrm{X}$ & $\mathrm{X}$ \\
\hline & Cefapirina & 60 & - & - & $\mathrm{X}$ \\
\hline & Cefazolina & 50 & - & - & $\mathrm{X}$ \\
\hline & Cefaperazona & 50 & - & - & $\mathrm{X}$ \\
\hline & Cloxacilina & 30 & - & $\mathrm{X}$ & - \\
\hline & Dicloxacilina & 30 & - & $\mathrm{X}$ & $\mathrm{X}$ \\
\hline & Neomicina & 500 & - & - & $\mathrm{X}$ \\
\hline & Ampicilina & 4 & - & $\mathrm{X}$ & $\mathrm{X}$ \\
\hline & Amoxicilina & 4 & - & $\mathrm{X}$ & $\mathrm{X}$ \\
\hline & Oxacilina & 30 & - & $\mathrm{X}$ & $\mathrm{X}$ \\
\hline & Penicilina G & 4 & - & $\mathrm{X}$ & $\mathrm{X}$ \\
\hline & Penicilina V & 4 & - & $\mathrm{X}$ & - \\
\hline \multirow[t]{4}{*}{ Tetraciclinas } & Tetraciclina & 100 & - & $\mathrm{X}$ & $\mathrm{X}$ \\
\hline & Oxitetraciclina & 100 & - & $\mathrm{X}$ & $\mathrm{X}$ \\
\hline & Clortetraciclina & 100 & - & $\mathrm{X}$ & $\mathrm{X}$ \\
\hline & Doxiciclina & 100 & - & $\mathrm{X}$ & - \\
\hline Macrolídeo & Eritromicina & 40 & - & - & $\mathrm{X}$ \\
\hline Aminoglicosídeo & Diidroestreptomicina/ Estreptomicina & 200 & - & - & $\mathrm{X}$ \\
\hline \multirow[t]{3}{*}{ Anfenicóis } & Cloranfenicol & 0,3 & 0,3 & $\mathrm{X}$ & - \\
\hline & Florfenicol & - & - & - & $\mathrm{X}$ \\
\hline & Tianfenicol & 50 & - & - & $\mathrm{X}$ \\
\hline \multirow[t]{9}{*}{ Sulfonamidas } & Sulfatiazol & 100 & 10 & $\mathrm{X}$ & $\mathrm{X}$ \\
\hline & Sulfametazina & 100 & 10 & $\mathrm{X}$ & $\mathrm{X}$ \\
\hline & Sulfadimetoxina & 100 & 10 & $\mathrm{X}$ & - \\
\hline & Sulfaclorpiridazina & 100 & - & $\mathrm{X}$ & - \\
\hline & Sulfadiazina & 100 & 10 & $\mathrm{X}$ & - \\
\hline & Sulfadoxina & 100 & - & $\mathrm{X}$ & - \\
\hline & Sulfamerazina & 100 & - & $\mathrm{X}$ & - \\
\hline & Sulfametoxazol & 100 & 10 & $\mathrm{X}$ & $\mathrm{X}$ \\
\hline & Sulfaquinoxalina & 100 & 10 & $\mathrm{X}$ & - \\
\hline \multirow[t]{4}{*}{ Nitrofuranos } & Nitrofurazona (SEM) & - & 1 & $\mathrm{X}$ & - \\
\hline & Furazolidona (AOZ) & - & 1 & $\mathrm{X}$ & - \\
\hline & Furaltadona (AMOZ) & - & 1 & $\mathrm{X}$ & - \\
\hline & Nitrofurantoína (AHD) & - & 1 & $\mathrm{X}$ & - \\
\hline \multirow[t]{3}{*}{ Quinolona/ fluoroquinolona } & Flumequina & 50 & - & $\mathrm{X}$ & - \\
\hline & Ciprofloxacina & 100 & - & $\mathrm{X}$ & - \\
\hline & Enrofloxacina & 100 & - & $\mathrm{X}$ & - \\
\hline Anticoccidiano & Lasalocida & - & 10 & $\mathrm{X}$ & - \\
\hline \multicolumn{6}{|l|}{ Antiparasitários } \\
\hline \multirow[t]{5}{*}{ Avermectinas } & Abamectina & $5 / 10^{*}$ & - & $\mathrm{X}$ & $\mathrm{X}$ \\
\hline & Doramectina & 15 & - & $\mathrm{X}$ & $\mathrm{X}$ \\
\hline & Eprinomectina & 20 & - & $\mathrm{X}$ & - \\
\hline & Ivermectina & 10 & - & $\mathrm{X}$ & $\mathrm{X}$ \\
\hline & Moxidecitina & 10 & - & $\mathrm{X}$ & - \\
\hline Benzimidazol & Albendazol & 100 & - & $\mathrm{X}$ & - \\
\hline
\end{tabular}

a. MAPA, 2012 ${ }^{104}$; b. ANVISA, 20097; * PAMVet $=5 \mu \mathrm{g} / \mathrm{L}$ ou $\mu \mathrm{g} / \mathrm{kg}$ e PNCRC $=10 \mu \mathrm{g} / \mathrm{L}$ ou $\mu \mathrm{g} / \mathrm{kg}$.

agropecuários em estabelecimentos sob Serviço de Inspeção Federal (SIF), identificadas, embaladas, congeladas e levadas para os laboratórios oficiais e os credenciados pelo MAPA e acreditados pelo INMETRO (ABNT ISO/IEC 17025:2005) para análise. ${ }^{17,105}$ Para produtos cárneos é realizada a triagem utilizando kits para teste microbiológico e as amostras "reagente positiva" são submetidas a análises confirmatórias por LC-MS/MS utilizando métodos validados de acordo com as orientações da União Europeia. ${ }^{98}$ Quando não há kits disponíveis, as análises são realizadas por método de triagem utilizando LC-MS/MS. ${ }^{17}$ Não há informação específica para os métodos utilizados para análise de leite e ovos, mas é provável que a rotina analítica seja similar à utilizada para produtos cárneos. 
A Tabela 3 mostra os dados do PNCRC referentes às análises de leite e ovos no período 2006-2012, com o número de análises realizadas para cada analito e o número de amostras não conforme. ${ }^{106-112} \mathrm{~A}$ não conformidade pode estar relacionada à presença de resíduos acima do LMR ou de resíduos de uma substância proibida. O número total de amostras coletadas em cada ano não está disponível, bem como o número de amostras contendo resíduos abaixo do LMR. Dentre os analitos monitorados, foram encontrados resíduos de avermectinas em leite acima do LMR em 12 amostras no período de 2006 a 2008, 8 amostras contendo ivermectina e 4 amostras com doramectina. A confirmação da presença desses resíduos em leite indica que, mesmo não recomendado, esses medicamentos são usados em vacas no período de lactação. Em 2012, uma amostra de leite continha oxitetraciclina acima do LMR.

No período de 2006-2009, somente cloranfenicol e nitrofuranos (metabólitos) foram analisados em amostras de ovos, com sulfonamidas e outros medicamentos sendo incluídos no Programa a partir de 2010. Nenhuma amostra de ovo analisada entre 2006 e 2012 apresentou resíduos dos analitos pesquisados. Atualmente, 114 produtos comerciais registrados (18\%) possuem os princípios ativos monitorados autorizados para aves. Os produtos contêm tetraciclinas (clortetraciclina, oxitetraciclina, doxiciclina), sulfonamidas (sulfatiazol, sulfametazina, sulfadimetoxina, sulfaclorpiridazina, sulfadiazina, sulfametoxazol e sulfaquinoxalina), $\beta$-lactâmicos (penicilina, amoxicilina, ampicilina e ceftiofur), quinolona (ciprofloxacina), macrolídeo (eritromicina) e aminoglicosídeo (estreptomicina). ${ }^{24}$ Porém, destes, somente as sulfonamidas começaram a ser analisadas/monitoradas em ovos pelo PNCRC a partir de 2010.
Substâncias proibidas como cloranfenicol e nitrofuranos não foram encontrados nas amostras de leite e ovos analisadas no PNCRC. Porém, resíduos dos metabólitos de nitrofuranos (nitrofurazona, furaltadona, nitrofurazona e furazolidona) foram encontrados em amostras de músculo de aves coletadas entre 2007 a 2011, todos acima de 1,0 $\mathrm{ug} / \mathrm{kg}$ (limite mínimo de performance requerida, estabelecido para substâncias sem LMR), indicando o uso ilegal desses medicamentos em aves no Brasil. ${ }^{106-110}$

\section{PAMVet/ANVISA}

O programa PAMVet foi criado pela ANVISA em 2002 com o objetivo de complementar as ações do MAPA e analisar o alimento pronto para consumo adquirido no comércio. ${ }^{7} \mathrm{O}$ leite foi escolhido como o primeiro alimento a ser monitorado no âmbito do programa, principalmente devido ao seu alto consumo pela população brasileira, principalmente crianças. ${ }^{113}$ No PAMVet, as amostras são coletadas em pontos de venda pelas Vigilâncias Sanitárias Estaduais (VISAs) e enviadas na embalagem original para os laboratórios credenciados para análise. A amostragem segue também o plano de amostragem do comitê Codex Alimentarius. A Tabela 4 mostra os métodos de triagem e confirmação utilizados no programa. As análises de estreptomicina e neomicina são realizadas com kits específicos, sem confirmação posterior por cromatografia. As sulfonamidas e avermectinas são analisadas diretamente por HPLC-FL.

Nos dois primeiros anos do PAMVet (2002/2003) foram coletadas 750 amostras de leite, $87 \%$ delas de leite longa vida (UHT) e 13\% de leite em pó. ${ }^{113}$ Neste período, tetraciclinas e $\beta$-lactâmicos foram

Tabela 3. Resultado das amostras de leite e ovos analisadas pelo PNCRC/MAPA no período de 2006 a 2012

\begin{tabular}{|c|c|c|c|}
\hline Ano & $\begin{array}{l}\text { Total de análises } \\
\text { concluídas }\end{array}$ & $\begin{array}{l}\text { Compostos ou classes analisadas } \\
\text { (análises concluídas) }\end{array}$ & $\begin{array}{l}\geq \mathrm{LMR} \\
\mathrm{N}^{\mathrm{e}}\end{array}$ \\
\hline \multicolumn{4}{|l|}{ Leite } \\
\hline 2006 & 289 & antibióticos $(99)^{\mathrm{a}}$, sulfonamidas (65) e avermectinas (125), & $\begin{array}{l}\text { Ivermectina, } 2 \\
\text { Doramectina, } 4\end{array}$ \\
\hline 2007 & 269 & tetraciclinas (116), sulfonamidas (67) e avermectinas (86) & Ivermectina, 1 \\
\hline 2008 & 250 & tetraciclinas (80), sulfonamidas (56) e avermectinas (114) & Ivermectina, 5 \\
\hline 2009 & 421 & tetraciclinas (159), cloranfenicol (60), sulfonamidas (61), avermectinas (74), albendazol (67) & Não detectado \\
\hline 2010 & 437 & tetraciclinas (154), cloranfenicol (60), sulfonamidas (76), avermectinas (71) e albendazol (76) & Não detectado \\
\hline 2011 & 384 & antimicrobianos $(73)^{\mathrm{b}}$, cloranfenicol (83), avermectinas (152) e albendazol (76) & Não detectado \\
\hline 2012 & 348 & $\begin{array}{l}\text { antimicrobianos }(75)^{\mathrm{c}} \text {, cloranfenicol e florfenicol }(72) \text {, avermectinas (151), trimetoprim e } \\
\text { albendazol (50) }\end{array}$ & Oxitetraciclina, 1 \\
\hline Total & 2398 & $\begin{array}{l}\text { antibióticos }{ }^{\mathrm{a}}(99) \text {, sulfonamidas (325), avermectinas }(773) \text {, tetraciclinas }(509) \text {, cloranfenicol } \\
(275) \text {, florfenicol }(72) \text {, albendazol }(269) \text {, antimicrobiano }(148)^{\mathrm{b}, \mathrm{c}} \text {, trimetoprim }(50)\end{array}$ & $\begin{array}{l}\text { Avermectinas, } 12 \\
\text { Oxitetraciclina, }\end{array}$ \\
\hline \multicolumn{4}{|c|}{ I } \\
\hline 2006 & 189 & cloranfenicol (76) e nitrofuranos ${ }^{\mathrm{d}}(113)$ & Não detectado \\
\hline 2007 & 172 & cloranfenicol (68) e nitrofuranos $^{\mathrm{d}}(104)$ & Não detectado \\
\hline 2008 & 170 & cloranfenicol (79) e nitrofuranos $^{\mathrm{d}}(91)$ & Não detectado \\
\hline 2009 & 175 & cloranfenicol (75) e nitrofuranos ${ }^{\mathrm{d}}(100)$ & Não detectado \\
\hline 2010 & 237 & $\begin{array}{l}\text { cloranfenicol (76), sulfonamidas }(60) \text { e } \\
\text { nitrofuranos }^{\mathrm{d}}(101)\end{array}$ & Não detectado \\
\hline 2011 & 311 & $\begin{array}{l}\text { cloranfenicol (75), sulfonamidas (75), lasalocida (31), enrofloxacina e ciprofloxacina (30) e } \\
\text { nitrofuranos }^{\mathrm{d}}(100)\end{array}$ & Não detectado \\
\hline 2012 & 277 & $\begin{array}{l}\text { anticoccidianos (103), nitrofuranos }{ }^{\mathrm{d}}(30) \text {, cloranfenicol (36), sulfonamidas }(75) \text {, enrofloxacina } \\
\text { e ciprofloxacina (33) }\end{array}$ & Não detectado \\
\hline Total & 1531 & $\begin{array}{l}\text { cloranfenicol (485), nitrofuranos }{ }^{\mathrm{d}}(639) \text {, sulfonamidas (210), anticoccidianos (103), lasalocida } \\
\text { (31), enrofloxcina e ciprofloxacina (63) }\end{array}$ & Não detectado \\
\hline
\end{tabular}


Tabela 4. Métodos de triagem e confirmação utilizados pelo PAMVet (ANVISA, 2006)

\begin{tabular}{|c|c|c|}
\hline & Triagem & Confirmação \\
\hline $\begin{array}{l}\text {-lactâmicos } \\
\text { Penicilinas } \\
\text { Benzilpenicilina } \\
\text { Amoxicilina } \\
\text { Dicloxacina } \\
\text { Cloxacilina } \\
\text { Cefalosporinas } \\
\text { Ceftiofur } \\
\text { Cefapirina }\end{array}$ & $\begin{array}{l}\text { SNAP }^{\circledast} \text { Betalactâmicos } \\
\text { LOD: } 4 \mu \mathrm{g} / \mathrm{L}\end{array}$ & $\begin{array}{l}\text { LC-MS } \\
\mathrm{LOD}=3-25 \mu \mathrm{g} / \mathrm{L}\end{array}$ \\
\hline Tetraciclinas & $\begin{array}{l}\text { SNAP }^{\circledast} \text { Tetraciclinas } \\
\text { LOD: } 4 \mu \mathrm{g} / \mathrm{L}\end{array}$ & $\begin{array}{l}\text { HPLC-UV/Vis } \\
\text { LOD }=4 \mu \mathrm{g} / \mathrm{L}\end{array}$ \\
\hline $\begin{array}{ll}\text { Anfenicóis } & \mathrm{I} \\
\text { Cloranfenicol } & \mathrm{I} \\
\text { Tianfenicol } & \mathrm{I} \\
\text { Florfenicol } & \\
\end{array}$ & $\begin{array}{l}\text { Ridascreen }^{\circledast} \text { chloramphenicol } \\
\text { LOD: } 37,5^{*} ; 50^{* *} \mu \mathrm{g} / \mathrm{L} \\
\text { LOQ }=50^{*} ; 150^{* *} \mu \mathrm{g} / \mathrm{L}\end{array}$ & $\begin{array}{l}\text { LC-MS: LOD e LOQ, } \mu \mathrm{g} / \mathrm{L} \\
0,3 \text { e } 0,8 \\
0,1 \text { e } 0,8\end{array}$ \\
\hline Estreptomicina & $\begin{array}{l}\text { Ridascreen }{ }^{\circledast} \text { streptomcina } \\
\text { LOD: } 20 \mu \mathrm{g} / \mathrm{L}\end{array}$ & Não realizada \\
\hline Neomicina & $\begin{array}{l}\text { Ridascreen }{ }^{\oplus} \text { Neomicina } \\
\text { LOD: } 60 \mu \mathrm{g} / \mathrm{L}\end{array}$ & Não realizada \\
\hline $\begin{array}{l}\text { Sulfonamidas } \\
\text { Sulfatiazol } \\
\text { Sulfametazina } \\
\text { Sulfadimetoxina } \\
\end{array}$ & Não realizada & $\begin{array}{l}\text { HPLC-FL:LODeLOQ, } \mu \mathrm{g} / \mathrm{L} \\
0,08^{*} ; 0,37^{* *} \mathrm{e} 0,10^{*} ; 0,33^{* *} \\
0,12^{*} ; 0,48^{* *} \mathrm{e} 0,24^{*} ; 1,24^{* *} \\
0,30^{*} ; 1,1^{* *} \text { e } 0,36^{*} ; 1,6^{* *} \\
\end{array}$ \\
\hline $\begin{array}{c}\text { Avermectinas } \\
\text { Abamectina } \\
\text { Doramectina }\end{array}$ & Não realizada & $\begin{array}{l}\text { HPLC-FL } \\
\text { LOD: } 0,6 \mu \mathrm{g} / \mathrm{L} \\
\text { LOQ: } 1,0 \mu \mathrm{g} / \mathrm{L}\end{array}$ \\
\hline
\end{tabular}

Ivermectina

LOD-= limite de detecção; LOQ= limite de quantificação; * leite em pó; ** leite UHT. Adaptado de ANVISA, 2009.

analisadas por métodos de triagem e confirmação, além de avermectinas por HPLC-FL (312 amostras em 2003). No total, 15 amostras foram confirmadas para tetraciclinas, e 8 das 722 amostras analisadas para $\beta$-lactâmicos foram positivas na triagem, mas o resultado não foi confirmado por HPLC-UV/Vis. No total, 150 amostras continham resíduos de avermectinas (abamectina, doramectina e/ou ivermectina), representando $48 \%$ das 312 amostras analisadas para avermectinas. A ivermectina foi o resíduo mais encontrado (123 amostras), todas com resíduos abaixo do LMR (10 $\mu \mathrm{g} / \mathrm{L}$, Tabela 2). Abametina ou doramectina foram encontradas em 23 amostras, sendo consideradas insatisfatórias devido à ausência de LMR estabelecido na época. Em 19 amostras, houve a detecção simultânea de abamectina e ivermectina. Esses resultados confirmam o uso de avermectinas em animais em lactação.

Em 2004 foram analisadas 312 amostras, sendo 281 de leite UHT e 31 de leite em pó. ${ }^{114}$ Testes de triagem mostraram 3 amostras de leite em pó positivas para $\beta$-lactâmicos, e 21 amostras positivas para tetraciclinas, sendo seis amostras de leite UHT $(2,1 \%)$ e 15 amostras de leite em pó $(48,4 \%)$. Das 306 amostras avaliadas para anfenicóis, $22(7,2 \%)$ foram positivas, sendo $13(5 \%)$ de leite UHT e nove (28\%) de leite em pó. Das 230 amostras analisadas para neomicina, 36 foram positivas na triagem $(16 \%)$. Nenhum dos resultados anteriores foi confirmado por métodos cromatográficos. No total, 308 amostras foram analisadas para dihidroestreptomicina/estreptomicina, mas o número de amostras positivas não foi reportado no relatório. Resíduos de abamectina foram encontrados em 25 amostras de leite UHT $(8,9 \%)$ e em 9 amostras de leite em pó (29\%), doramectina em 2 amostras em leite UHT e ivermectina em 150 amostras de leite UHT $(51,7 \%)$ e 19 amostras de leite em pó $(61,3 \%)$. Nos anos 2005 e 2008 não foram coletadas amostras devido a reestruturações internas do programa.
Os resultados individuais do PAMVet referentes aos períodos de 2006/2007 e 2009/2010 foram disponibilizados para este estudo pela Coordenação do Programa. A ANVISA também disponibilizou no seu site o relatório do programa relativo ao período $2006 / 2007 .{ }^{7} \mathrm{No}$ período 2006/2007 foram analisadas 615 amostras (77,2\% UHT e $22,8 \%$ em pó) e 711 amostras (50,3\% leite UHT, 27,8\% leite em pó e $21,8 \%$ leite pasteurizado) foram analisadas em 2009/2010.

A Figura 1 mostra os resultados obtidos em 2006/2007 e 2009/2010. De uma maneira geral, o percentual de amostras positivas foi maior para leite em pó, resultado esperado já que os resíduos nestes produtos se encontram concentrados. Como nos anos anteriores, as avermectinas foram os medicamentos mais detectados nas amostras de leite, com percentuais menores de amostras positivas em 2009/2010 (Figura 1). Cerca de 17\% das 155 amostras de leite pasteurizado analisadas em 2009/2010 foram positivas (Figura 1). Ivermectina foi o resíduo mais encontrado nas amostras, correspondendo, em média a $82 \%$ dos resíduos de avermectinas encontradas nas amostras nos dois períodos. Resíduos de doramectina corresponderam a cerca de $10 \%$ dos resíduos do grupo.

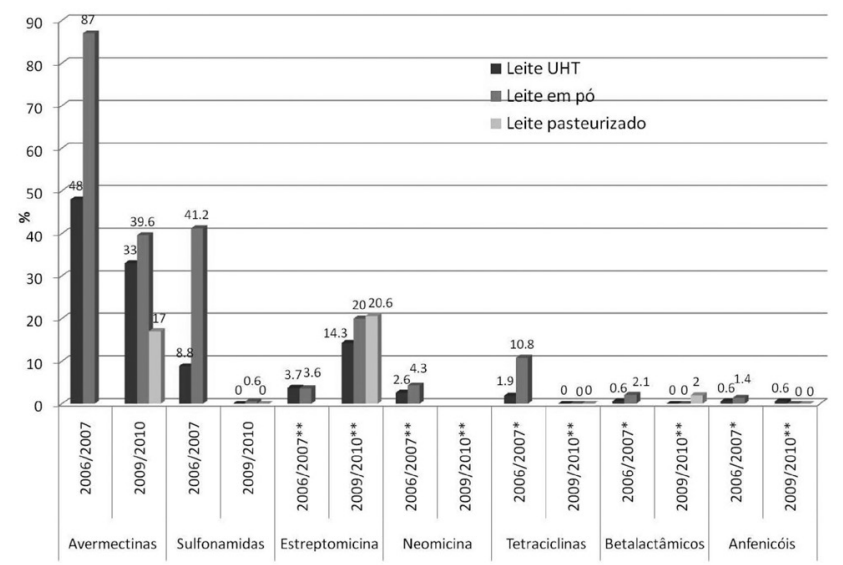

Figura 1. Percentual de amostras de leite positivas para drogas veterinárias analisadas pelo PAMVet em 2006/2007 e 2009/2010. * resultado confirmado; ** triagem

Em 2009/2010, somente uma amostra de leite (em pó) analisada continha resíduos de sulfonamidas, um resultado bem inferior ao encontrado no período anterior (41,2\% das 119 amostras de leite em pó analisadas) (Figura 1). Um percentual maior de amostras positivas para a estreptomicina foi encontrado nesse período ( $20 \%$ das amostras de leite em pó e pasteurizado) comparado com o anterior utilizando teste de triagem específico para este medicamento (ver Tabela 4). Duas amostras de leite em pó e 3 de leite UHT continham

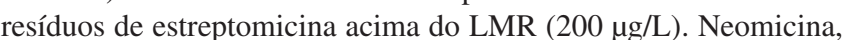
$\beta$-lactâmicos e anfenicóis foram positivas em menos de 5\% das amostras analisadas. Resíduos de anfenicóis abaixo do LOQ do método foram confirmados em 2006/2007 (3 amostras de leite UHT contendo cloranfenicol e 2 de leite em pó contendo florfenicol). Cerca de $10 \%$ das 139 amostras de leite em pó analisadas em 2006/2007 continham resíduos de tetraciclinas ( 10 de clortetraciclina, 4 de tetraciclina e 1 de oxitetraciclina), mas nenhuma amostra analisada em 2009/2010 foi positiva para este grupo no teste de triagem (Figura 1).

\section{Estudos publicados na literatura}

\section{Brasil}

No Brasil, vários trabalhos reportam a presença de resíduos de medicamentos em leite, a maioria utilizando métodos de triagem, sem dados de confirmação e quantificação. ${ }^{46,115-117}$ Numa ampla revisão 
sobre o tema publicada recentemente, ${ }^{46} 27$ dos 35 trabalhos avaliados que investigaram a presença de antimicrobianos em leite no país não reportaram nenhuma amostra com resíduos acima do LMR e 7 estudos apresentaram resultados não conforme, inclusive pela presença de anfenicóis. Dentre os 10 trabalhos que reportaram dados de resíduos de antiparasitários (avermectinas e albendazol), cinco apresentaram resultados de amostras contendo resíduos acima do LMR.

Outros estudos conduzidos no Brasil, não citados nesta revisão, confirmam estes achados. Em São Paulo, amostras de leite obtidas em supermercado e analisadas por HPLC-MS/MS (extração ELL) apresentaram resíduos de cloranfenicol $(4,73 \mathrm{ng} / \mathrm{kg})$ em uma das 4 amostras de leite integral analisadas e em duas $(5,9$ e $6,10 \mathrm{ng} / \mathrm{kg})$ das 3 amostras de leite em pó analisadas. ${ }^{69}$ Em estudo conduzido no Rio Grande do Sul, resíduos de doramectina abaixo do LOQ (1,2 ng/ $\mathrm{mL}$ ) foram encontradas em uma das 22 amostras de leite extraídas utilizando ELL-PBT e análise por HPLC-FL e LC-MS/MS. ${ }^{54}$

Poucos estudos conduzidos no país relatam a incidência de medicamentos veterinários em ovos. A presença de resíduos de antibióticos ionóforos poliéteres, macrolídeos e lincosamida foi avaliada em amostras de ovo obtidas no comércio do Rio de Janeiro, extraídas com acetonitrila e analisadas por LC-MS/MS.$^{63} \mathrm{O}$ número de amostras não foi reportado, porém os resíduos encontrados estavam abaixo do LOQ do método (14-15.3 $\mu \mathrm{g} / \mathrm{L})$. Em outro estudo, o mesmo grupo analisou 100 amostras de ovos, encontrando $30 \%$ das amostras contendo pelo menos um resíduo, sendo $25 \%$ contendo resíduos de ionóforos poliéteres, principalmente salinomicina (21 amostras; 0,05 - $53 \mu \mathrm{g}$ / $\mathrm{kg}) .{ }^{118}$ No âmbito do PNCRC em 2005/2006, foi avaliada a presença de resíduos de cloranfenicol e florafenicol, medicamentos proibidos no Brasil, em 60 amostras de ovos. Nenhuma amostra apresentou resíduos acima do LOQ $(0,1 \mathrm{ng} / \mathrm{g}) .{ }^{119}$

\section{Outros países}

A literatura de resíduos de medicamentos veterinários em leite e ovos no âmbito internacional é extensa e alguns estudos são reportados nesta revisão. Na Suiça, foram analisadas 150 amostras de leite e foram encontradas $4(2,7 \%)$ amostras contendo tetraciclina, sulfaquinoxalina, cefalexina e penicilina $\mathrm{G}$, esta última no nível de $30 \mu \mathrm{g} / \mathrm{L}$, acima do LMR. ${ }^{50} \mathrm{Na}$ Croácia foram reportados os resultados de análise de resíduos de antibióticos em 1259 amostras de leite cru coletadas no período de 2008 a 2010. ${ }^{120}$ Teste microbiológico detectou 36 amostras positivas, mas somente uma foi confirmada. Teste de imunoensaio mostrou uma amostra positiva para tetraciclinas, resultado confirmado por HPLC-DAD $(1671 \mu \mathrm{g} / \mathrm{L})$.

Dez amostras de leite foram analisadas na Espanha utilizando QuEChERS, sem a etapa de clean up dispersivo, sendo encontrados traços de tilosina e fembendazol (<LOQ $3 \mu \mathrm{g} / \mathrm{kg}$ ) em 2 amostras. ${ }^{14}$ Também na Espanha, foram analisadas 100 amostras de leite cru de fazenda e 15 amostras de leite do comércio utilizando ELL com acetonitrila e clean up com cartucho Strata ${ }^{\mathrm{TM}}-\mathrm{X} .^{48}$ Apenas uma amostra apresentou resultado positivo, para decoquinato, um coccidioestático, na concentração de $1 \mathrm{ng} / \mathrm{mL}$. Resíduos de lincomicina foram encontrados em 16 das 17 amostras de leite analisadas por UPLC-MS/ MS em Taiwan, todas com resíduos abaixo do LMR (150 ng/mL) ${ }^{67}$

Na Espanha, das 11 amostras de ovos analisadas por LC-MS/ MS, 4 amostras apresentaram resíduos de eritromicina, enrofloxacina, tiabendazol, emamectina febendenzol e/ou difloxacina ${ }^{88} \mathrm{Uma}$ das amostras continha eritromicina acima do LMR $(433 \mu \mathrm{g} / \mathrm{kg})$. Na Coréia, 66 amostras de leite e 66 de ovos foram analisadas por LCMS/MS, sendo encontrada uma amostra de ovo contendo lincomicina (25 ng/g), abaixo do LMR. ${ }^{79}$

Em 2007, o programa de monitoramento francês analisou 10 anticoccidianos em 100 amostras de ovos por LC-MS/MS, encontrando 20 amostras com um ou mais resíduos abaixo do LMR e 29 amostras não conformes, sendo 18 por conterem nicarbazina, 7 por conterem diclazuril e 7 por conterem robenidina, medicamentos não permitidos em aves poedeiras. ${ }^{121} \mathrm{Na}$ Itália, 2 das 27 amostras de ovos analisadas continham oxitetraciclina ( 35 e $62 \mu \mathrm{g} / \mathrm{kg}$ ), ambas abaixo do LMR. ${ }^{122}$ Das 30 amostras adquiridas no comércio chinês e analisadas quanto à presença de tetraciclinas por HPLC-UV, 5 foram positivas. ${ }^{123}$ Ainda na China, foram encontrados florfenicol e florfenicol amina nas concentrações de 19 e $36 \mu \mathrm{g} / \mathrm{kg}$, respectivamente, em apenas uma amostra das 50 amostras analisadas por HPLC-FL. ${ }^{124}$

Alguns estudos avaliaram os níveis de resíduos de antimicrobianos e antibióticos em ovos após administração oral dos medicamentos em galinhas. Em um estudo, administrou-se enrofloxacina em galinhas por 4 dias $(10 \mathrm{mg} / \mathrm{kg}$ pc/dia) e seus ovos foram recolhidos durante 15 dias para análise. ${ }^{125}$ A concentração máxima de enrofloxacina foi observada 2 dias após o término do tratamento ( 3000 ng/g), seguido de um rápido declínio. Ovos de galinhas tratadas com tilosina e doxiciclina ( 75 e $150 \mathrm{mg} / \mathrm{kg}$ pc dia, respectivamente) continham $138 \mu \mathrm{g} / \mathrm{kg}$ de tilosina e $3800 \mu \mathrm{g} / \mathrm{kg}$ de doxicilina ao final dos 5 dias de tratamento, e 16 e $147 \mu \mathrm{g} / \mathrm{kg}$, respectivamente, 5 dias após seu termino. ${ }^{76}$

Ovos de aves tratadas com enrofloxacina por 3 dias $(50 \mathrm{mg} / \mathrm{kg}$ pc dia) continham $1400 \mathrm{ng} / \mathrm{g}$ do medicamento logo após o término do tratamento, níveis que caíram para $\sim 3 \mathrm{ng} / \mathrm{g}$ após 16 dias. ${ }^{126} \mathrm{O}$ metabólito ciprofloxacina foi detectado até o oitavo dia após o tratamento. Em outro estudo, ovos de aves tratadas com eritromicina por 5 dias consecutivos ( $1500 \mathrm{~g} / \mathrm{L}$ eritromicina 20\%), apresentaram 135 $\mathrm{ng} / \mathrm{g}$ do composto um dia após o termino da aplicação, caindo para 20 ng/g dois dias depois, níveis inferiores ao LMR dessa substância $(150 \mathrm{ng} / \mathrm{g}) .^{127}$

\section{CONCLUSÃO}

Animais produtores de alimentos são frequentemente tratados com medicamentos veterinários em ações profiláticas, terapêuticas e/ou como promotores de crescimento. $\mathrm{O}$ uso desses medicamentos, porém, pode deixar resíduos nos alimentos, como carne, ovos e leite, e a exposição humana pela dieta pode representar um risco à saúde. Com o objetivo de regular este uso, o Codex Alimentarius e agências reguladoras nacionais ou regionais estabelecem limites máximos de resíduos (LMR) para cada medicamento com uso aprovado em matrizes onde estes resíduos são esperados. Testes de imunoensaio ou microbiológicos podem ser usados numa etapa de triagem para determinação da presença desses resíduos nos alimentos, mas resultados positivos devem ser confirmados por métodos cromatográficos. Vários estudos publicados na literatura descrevem o procedimento analítico e sua performance, principalmente para leite. Em geral, os resíduos são extraídos com acetonitrila, purificados por EFS ou diretamente analisado por LC-MS/MS. Resultados dos programas de monitoramento de resíduos de medicamentos veterinários da ANVISA e do MAPA mostraram que as avermectinas, principalmente a ivermectina, foram os principais compostos encontrados nas amostras de leite analisadas. $\mathrm{O}$ uso destes produtos no gado no período de lactação não é recomendado, mas estes resultados mostram que este uso é frequente.

Somente o programa de monitoramento do MAPA inclui análise de ovos e poucos estudos no Brasil analisam esta matriz. Estudos conduzidos em outros países com aves tratadas oralmente mostraram que resíduos são esperados em ovos, indicando a necessidade de incluir esta matriz também no programa da ANVISA, que visa principalmente o consumidor interno. Dados de monitoramento de resíduos de medicamentos veterinários são essenciais para avaliar a exposição humana a estes compostos e o potencial risco para a saúde do consumidor. Desta maneira, é essencial que os programas governamentais sejam mantidos e ampliados para viabilizar a condução destes estudos. 


\section{REFERENCIAS}

1. Sarmah, A. K.; Meyer, M. T.; Boxall, A. B. A.; Chemosphere 2006, 65, 725 .

2. Stolker, A. A. M.; Brinkman, U. A. T.; J. Chromatogr. A 2005, 1067, 15.

3. Andrée, S. Jira, W.; Schwind, K. H.; Wagner H.; Schwägele, F.; Meat Science 2010, 86, 38.

4. Netto, D. P.; Lopes, M. O.; de Oliveira, M. C. S.; Nunes, M. P.; Machinski Jr., M.; et al.; Acta Scientiarum. Animal Sciences 2005, 27, 145.

5. ftp://ftp.fao.org/codex/Publications/ProcManuals/Manual_20e.pdf, acessada em Setembro 2013

6. Kennedy, D. G.; Cannavan, A.; McCracken, R. J.; J. Chromatogr. A 2000, $882,37$.

7. Agência Nacional de Vigilância Sanitária (ANVISA), Relatório PAMVet, 2009. Disponível em: www.anvisa.gov.br, acessada em Setembro 2013.

8. Le Bizec, B.; Pinel, G.; Antignac, J.; J. Chromatogr. A 2009, 1216, 8016.

9. Littlefield, N. A.; Sheldon, W. G.; Allen, R.; Gaylor, D. W.; Food Chem. Toxicol. 1990, 28, 157.

10. Dasenaki, M. E.; Thomaidis, N. S.; Anal. Chim. Acta 2010, 672, 93.

11. Witte. W.; Science 1998, 279, 996.

12. World Health Organization (WHO). 1994. Disponível em http:// whqlibdoc.who.int/hq/1995/who_cds_bvi_95.7.pdf, acessada em Setembro 2013

13. Nascimento, G. G. F.; Maestro, V.; Campos, M. S. P.; Rev. Nutr. 2001, $14,119$.

14. Luiz, M. M. A.; Vidal, J. L. M.; González, R. R.; Frenich, A. G.; J. Chromatogr. A 2008, 1205, 10.

15. Bittencourt M. S.; Martins, M. T.; de Albuquerque, F. G. S.; Barreto, F., Hoff, R.; Food Addit. Contam., Part A 2012, 29, 508.

16. Almeida, M. P.; Rezende, C. P.; Souza L. F.; Brito R. B.; Food Addit. Contam., Part A 2012, 29, 517.

17. Nonaka, C. K. V.; Oliveira, A. M. G.; Paiva, C. R.; Almeida, M. P.; Rezende, C. P.; Moraes, C. G. O.; Botelho, B. G.; Souza, L. F.; Dias, P. G.; Food Addit. Contam., Part A 2012, 29, 526.

18. Rezende, C. P.; Almeida, M. P.; Brito, R. B.; Nonaka, C. K.; Leite, M. O.; Food Addit. Contam., Part A 2012, 29, 541.

19. Magalhães, C. G.; De Paiva, C. R.; Botelho, B. G.; Oliveira, A. M. G.; De Souza, L. F.; Nonaka, C. V.; Santos, K. V.; Farias, L. M.; Carvalho, M. A. R.; Food Addit. Contam., Part A 2012, 29, 535.

20. Barreto, F.; Ribeiro, C.; Hoff, R. B.; Costa, T. D.; Food Addit. Contam., Part A 2012, 29, 550.

21. Taka, T.; Baras, M. C.; Bet, Z. F. C.; Food Addit. Contam., Part A 2012, $29,596$.

22. Jank, L.; Hoff, R. B.; Tarouco, P. C.; Barreto F.; Pizzolato, T. M.; Food Addit. Contam., Part A 2012, 29, 497.

23. http://www.agricultura.gov.br/animal, acessada em Setembro 2013.

24. http://www.cpvs.com.br/cpvs/index.html, acessada em Setembro 2013.

25. Di Corcia, A.; Nazzari, M.; J. Chromatogr. A 2002, 974, 53.

26. Rice, D. N.; Straw, B. E.; G92-1093 Use of Animal Drugs in Livestock Management. Historical Materials from University of Nebraska-Lincoln Extension. 1992. Paper 226

27. Yu, H.; Tao, Y.; Chen, D.; Wang, Y.; Yuan, Z.; Food Chem. 2011, 124, 1131.

28. Drincic, H. K.; Bazulic, D.; Postruznik, J.S.; Grubelic, M.; Stuhne, G.; J. Agric. Food Chem. 2003, 51, 871.

29. Brasil, 2009. Ministério da Agricultura Pecuária e Abastecimentos (MAPA). Instrução Normativa $\mathrm{N}^{\circ} 26,09$ de julho de 2009 publicada no DOU de 10/07/2009, Seção 1.

30. Dubois, M.; Fluchard, D.; Sior, E.; Delahaut, Ph.; J. Chromatogr. B 2001, 753, 189

31. Bogialli, S.; Curini, R.; Di Corcia, A.; Laganà, A.; Mele, M.; Nazzari, M.; J. Chromatogr. A 2005, 1067, 93.
32. USA. Chloramphenicol (Veterinary-Systemic). The United States Pharmacopeial Convention 2007. Disponível em http://vetmed.tamu.edu/common/ docs/public/aavpt/chloramphenicol.pdf, acessada em Setembro 2013.

33. National Institute of Enviromental Health Science. Chloramphenicol. Report on Carcinogens, Twelfth Edition (2011). USA National Toxicology Program, Department of Health and Human Services.

34. http://www.agricultura.gov.br/animal/qualidade-dos-alimentos/aditivosproibidos, acessada em Setembro 2013.

35. Australia. The NRA Review of sulphonamides. Final Report. National Registration Authority For Agricultural and Veterinary Chemicals. Camberra. Australia. 2000.

36. Hiraku, Y.; Sekine, A.; Nabeshi, H.; Midorikawa, K.; Murata, M.; Kumagai, Y.; Kawanishi, S.; Cancer Lett. 2004, 215, 141

37. Vass, M.; Hruska, K.; Franek, M.; Vet Med -Czech 2008, 53, 469.

38. Machado, J. A. C.; Oliveira, A. C.; Antônio, N. S.; Canesini, R.; Rocha, J. R.; Negri, D.; Pereira, D. M.; Revista Cienífica Eletrônica de Medicina Veterinária 2009, 12

39. Shoop, W. L.; Mrozik, H.; Fisher, M. H.; Vet. Parasitol. 1995, 59, 139.

40. Durden, D. A.; J. Chromatogr. B 2007, 850, 134.

41. Rubensam, G.; Barreto, F.; Hoff, R. B.; Pizzolato T. M.; Food Control 2013, 29, 55

42. Jasmer, D. P.; Yao, C.; Rehman, A.; Johnson, S.; Mol. Biochem. Parasitol. 2000, 105, 81

43. Toldra, F.; Reig, M.; Trends Food Sci. Technol. 2006, 17, 482.

44. Medical Subject Headings (MeSH). Disponível em http://www.ncbi.nlm. nih.gov/mesh/?term=elisa, acessada em Setembro 2013.

45. Nouws, J.; Egmond, H. V.; Smulders, I.; Loeffen, G.; Schouten, J.; Stegeman, H.; Int. Dairy J. 1999, 9, 85.

46. Ferreira, R. G.; Spisso, B.F.; Hora, I. M. C. da; Monteiro, M. A.; Pereira, M. U.; Costa, R. P. da; Carlos, B. de S.; Revista Seguança Alimentar Nutricional 2012, 19, 30

47. Hoff, R.; Ribarcki, F.; Zancanaro, I.; Castellano, L.; Spier, C.; Barreto, F.; Fonseca, S.H.; Food Addit. Contam., Part A 2012, 29, 577.

48. Nebot, C.; Iglesias, A.; Regal, P.; Miranda, J.; Cepeda, A.; Fente, C.; Int. Dairy J. 2012, 22, 78.

49. Aerts, M. M. L.; Hogenboom, A. C.; Brinkman, U. A. Th.; J. Chromatogr. $B$ 1995, 667, 1.

50. Ortelli, D.; Cognard, E.; Jan, P.; Edder, P.; J. Chromatogr. B 2009, 877, 2363.

51. Chiaradia, M. C.; Collins, C. H.; Jardim, I. C. S. F.; Quim. Nova 2008 , $31,62$.

52. Prestes, O. D.; Martins, M. L.; Friggi, C. A.; Munaretto, J. S.; Adaime, M. B.; Zanella, R.; Quim. Nova 2013, no prelo.

53. Spisso, B. F.; Araujo Jr., M. A. G.; Monteiro, M. A.; Lima, A. M. B.; Pereira, M. U.; Luiz, R. A.; Nóbrega A. W.; Anal. Chim. Acta 2009, 656, 72.

54. Rubensam, G.; Barreto, F.; Hoff, R. B.; Kista, T. L.; Pizzolato, T. M.; Anal. Chim. Acta 2011, 705, 24.

55. Goulart, S. M.; Queiroz, M. L. R.; Neves, A. A.; Queiroz, J. H.; Talanta 2008, 75,1320

56. Lopes, R. P.; Augusti, D. V.; de Souza, L. F.; Santos, F. A.; Lima, J. A.; Vargas, E. A.; Augusti R.; Anal. Methods 2011, 3, 606

57. Lopes, R. P.; Augusti, D. V.; Oliveira, A. G.; Oliveira, F. A.; Vargas, E. A.; Augusti R.; Food Addit. Contam., Part A 2013, 28, 1667.

58. Lehotay, S. J.; Maštovská, K.; Yun, S. J.; J. AOAC Int. 2005, 88, 630.

59. Giannetti, L.; Giorgi, A.; Necci, F.; Ferretti, G.; Buiarelli, F.; Neri, B.; Anal. Chim. Acta 2011, 700, 11.

60. Penney, L.; Smith, A.; Coates, B.; Wijewickreme, A.; J. AOAC Int. 2005, 88,645 .

61. Koesukwiwat, U.; Jayanta, S.; Leepipatpiboon, N.; J. Chromatogr. A 2007, 1149, 102

62. Koesukwiwat, U.; Jayanta, S.; Leepipatpiboon, N.; J. Chromatogr. A 2007, 1140, 147 
63. Spisso, B. F.; Ferreira, R. G.; Pereira, M. U.; Monteiro, M. A.; Cruz, T. Á.; Costa, R. P.; Lima, A. M. B.; Nóbrega, A. W.; Anal. Chim. Acta 2010, 682, 82 .

64. Spisso, B. F.; Jesus, A. L. O.; Araujo Jr., M. A. G.; Monteiro, M. A.; Anal. Chim. Acta 2007, 581, 108.

65. Dowling, G.; Gallo, P.; Malone, E.; Regan, L.; J. Chromatogr. A 2009, $1216,8117$.

66. Turnipseed, S. B.; Storey, J. M.; Clark, S. B.; Miller, K. E.; J. Agric. Food Chem. 2011, 59, 7569.

67. Tang, Y.; Lu, H.; Lin, H.; Shih, Y.; Hwang, D.; J. Chromatogr. B 2012, $881-882,12$

68. Tölgyesi, A.; Sharma, V. K.; Fekete, S.; Fekete, J.; Simon, A.; Farkas, S.; J. Pharm. Biomed. Anal. 2012, 64, 40.

69. Martins Jr., H. A.; Bustillos, O. V.; Pires, M. A.F.; Lebre, D. T.; Wang, A. Y.; Quim. Nova 2006, 29, 586.

70. González, R. R.; Luiz, M. M. A.; Bolanos, P. P.; Frenich, A. G.; Vidal J. L. M.; J. Chromatogr. A 2011, 1218, 9353.

71. Peters, R. J. B.; Bolck, Y. J. C.; Rutgers, P.; Stolker, A. A. M.; Nielen, M. W. F.; J. Chromatogr. A 2009, 1216, 8206.

72. Zhan, J.; Yu, X.; Zhong, Y.; Zhang, Z.; Cui, X.; Peng, J.; Feng, R.; Liu, X.; Zhu, Y.; J. Chromatogr. B 2012, 906, 48.

73. Malone, E.M.; Dowling, G.; Elliott, C.T.; Kennedy, D.G.; Regana, L.; J. Chromatogr. A 2009, 1216, 8132.

74. Rodziewicz, L., Zawadzka, I.; Talanta 2008, 75, 846.

75. Kaufmann, A.; Butcher, P.; Maden, K.; Walker, S.; Widmer, M.; Talanta 2011, 85, 991 .

76. Jiménez, V.; Rubies, A.; Centrich, F.; Companyó, R.; Guiterasa, J.; J. Chromatogr. A 2011, 1218, 1443.

77. Gremilogianni, A. M.; Megoulas, N. C.; Koupparis, M. A.; J. Chromatogr. A 2010, 1217, 6646.

78. Huang, X.; Qiu, N.; Yuan D.; J. Chromatogr. A 2009, 1216, 8240.

79. Kim, E.; Bahn, K.; Kang, E.; Kim, M.; Food Chem. 2012, 132, 1063.

80. Tian, H.; Chemosphere 2011, 83, 349.

81. Stubbings, G.; Bigwood, T.; Anal. Chim. Acta 2009, 637, 68.

82. Keegan, J.; Whelan, M.; Danahera, M.; Crooksd, S.; Sayerse, R.; Anastasio, A.; Elliott, C.; Brandon, D.; Furey, A.; O’Kennedy, R.; Anal. Chim. Acta 2009, 654, 111.

83. Mamani, M. C. V.; Reyes, F. G. R.; Rath, S.; Food Chem. 2009, 117, 545.

84. Mottier, P.; Parisod, V.; Gremaud, E.; Guy, P. A.; Stadler, R. H.; J. Chromatogr. A 2003, 994, 75 .

85. Guy, P. A.; Royer, D.; Mottier, P.; Gremaud, E.; Perisset, A.; Stadler, R. H.; J. Chromatogr. A 2004, 1054, 365.

86. Fritz, J. W.; Zuo, Y.; Food Chem. 2007, 105, 1297.

87. Ronning, H. T.; Einarsen, K.; Asp, T. N.; J. Chromatogr. A 2006, 1118, 226.

88. Frenich, A. G.; Luiz, M. M. A.; Vidal, J. L. M.; González, R. R.; Anal. Chim. Acta 2010, 661, 150.

89. Juhler, R. K.; J. Chromatogr. A 1997, 786, 145.

90. León, N.; Roca, M.; Igualada, C.; Martins, C. P. B.; Pastor, A.; Yusá, V.; J. Chromatogr. A 2012, 1258, 55.

91. Lopes, R. P.; Reyes, R. C.; González, R. R.; Frenich, A. G.; Vidal, J. L. M.; Talanta 2012, 89, 201.

92. Lopes, R.P.; Reyes, R. C.; González, R. R.; Vidal, J. L. M.; Frenich, A. G.; J. Chromatogr. B 2012, 895-896, 39.

93. Lopes, R. P.; Passos, E. E. F.; Filho, J. F. A.; Vargas, E. A.; Augusti, D. V.; Augusti, R.; Food Control 2012, 28, 192.

94. Anastassiades, M.; Mastovská, K.; Lehotay, S. J.; J. Chromatogr. A 2003, 1015, 163.

95. Brasil, Ministério da Agricultura Pecuária e Abastecimento; Manual de garantia da qualidade analítica, Ministério da Agricultura Pecuária e Abastecimento, Secretaria de Defesa Agropecuária, Brasília, 2011.
96. Paschoal, J. A. R.; Rath, S.; Airoldi, F. P. S.; Reyes, F. G. R.; Quim. Nova 2008, 31, 1190

97. Loco, J.V.; Jànosi, A.; Impens, S.; Fraselle, S.; Cornet, V.; Degroodt, J.M.; Anal. Chim. Acta 2007, 586, 8.

98. European Commission. 2002. Commission Decision of 12 August 2002 implemented Council Directive 96/23/EC concerning the performance of analytical methods and the interpretation of results (text with EEA relevance) (notified under document number C(2002) 3044). Off J Eur Comm. L 221:8-36.

99. Brasil, 1999. Ministério da Agricultura Pecuária e Abastecimento (MAPA). Instrução Normativa No 42, de 20 de Dezembro de 1999 publicada no DOU de 22/12/1999, Seção 1 , Página 213.

100. Ministério da Agricultura, Pecuária e do Abastecimento. 2006. Disponível em http://www.agricultura.gov.br/comunicacao/noticias/2006/03/ueconfirma-embargo-ao-mel-brasileiro, acessada em Setembro 2013.

101. Food and Veterinary Office. Response to draft report of European Community mission DG (SANCO) 7712/2005 to evaluate national programme on residues and contaminants in animals and animal products. Disponível em: http://ec.europa.eu/food/fvo/ir_search_en.cfm, acessada em Setembro 2013

102. Mauricio, A. Q.; Lins E. S.; Food Addit. Contam., Part A 2012, 29, 482.

103. Brasil. Ministério da Agricultura, Pecuária e do Abastecimento. Secretaria de Defesa Agropecuária. Instrução Normativa No. 9 de 30 de março de 2007. Plano Nacional de Controle de Resíduos em produtos de origem animal. 2007. Diário Oficial da União de 04 de abril de 2007. Brasília (Brasil).

104. Brasil. Ministério da Agricultura, Pecuária e do Abastecimento. Secretaria de Defesa Agropecuária.. Instrução Normativa No 11, de 22 de maio de 2012. Plano Nacional de Controle de Resíduos em produtos de origem animal. 2012. Diário Oficial da União de 25 de maio de 2012. Brasília (Brasil).

105. http://www.agricultura.gov.br/animal/qualidade-dos-alimentos/residuose-contaminantes, acessada em Setembro 2013.

106. Brasil. Ministério da Agricultura, Pecuária e do Abastecimento. Secretaria de Defesa Agropecuária. Instrução Normativa No. 8 de 30 de março de 2007. Plano Nacional de Controle de Resíduos em produtos de origem animal. 2006. Diário Oficial da União de 03 de abril de 2007. Brasília (Brasil).

107. Brasil. Ministério da Agricultura, Pecuária e do Abastecimento. Secretaria de Defesa Agropecuária. Instrução Normativa No. 9, de 10 de abril de 2008. Plano Nacional de Controle de Resíduos em produtos de origem animal. 2007. Diário Oficial da União de 17 de abril de 2008. Brasília (Brasil).

108. Brasil. Ministério da Agricultura, Pecuária e do Abastecimento. Secretaria de Defesa Agropecuária. Instrução Normativa No. 15, de 25 de Maio de 2009. Plano Nacional de Controle de Resíduos em produtos de origem animal. 2008. Diário Oficial da União de 28 de maio de 2009. Brasília (Brasil).

109. Brasil. Ministério da Agricultura, Pecuária e do Abastecimento. Secretaria de Defesa Agropecuária. Instrução Normativa No. 6, de 16 de março de 2010. Plano Nacional de Controle de Resíduos em produtos de origem animal. 2009. Diário Oficial da União de 23 de março de 2010. Brasília (Brasil).

110. Brasil. Ministério da Agricultura, Pecuária e do Abastecimento. Secretaria de Defesa Agropecuária. Instrução Normativa No. 6, de 25 de fevereiro de 2011. Plano Nacional de Controle de Resíduos em produtos de origem animal.2010. Diário Oficial da União de 28 de fevereiro de 2011. Brasília (Brasil).

111. Brasil. Ministério da Agricultura, Pecuária e do Abastecimento. Secretaria de Defesa Agropecuária. Instrução Normativa No. 7, de 4 de abril de 2012. Plano Nacional de Controle de Resíduos em produtos de origem animal. 2011. Diário Oficial da União de 05 de abril de 2012. Brasília (Brasil). 
112. Brasil. Ministério da Agricultura, Pecuária e do Abastecimento. Secretaria de Defesa Agropecuária. Instrução Normativa No. 7, de 27 de março de 2013. Plano Nacional de Controle de Resíduos em produtos de origem animal. 2012. Diário Oficial da União de 03 de abril de 2013. Brasília (Brasil).

113. Agência Nacional de Vigilância Sanitária (ANVISA), Relatório PAMVet, 2005 Programa de Análise de Resíduos de Medicamentos Veterinários em Alimentos de Origem Animal - PAMVet - Relatório 2002/2003 - Monitoramento de Resíduos em Leite Exposto ao Consumo ( $1^{\circ}$ e $2^{\circ}$ anos de atividades). Disponível em: www.anvisa.gov.br, acessada em Setembro 2013.

114. Agência Nacional de Vigilância Sanitária (ANVISA), Relatório PAMVet, 2006. Programa de Análise de Resíduos de Medicamentos Veterinários em Alimentos de Origem Animal - PAMVet. Relatório 2004/2005 - Monitoramento de Resíduos em Leite Exposto ao Consumo. Disponível em: www.anvisa.gov.br, acessada em Setembro 2013.

115. Fonseca, G. P.; Cruz, A. G.; Faria, J. A. F.; Silva, R.; Moura, M. R. L.; Carvalho, L. M. J.; Ciência e Tecnologia de Alimentos 2009, 29, 451.

116. Nero, L. A.; Mattos, M. R.; Beloti, V.; Barros M. A. F.; Franco, B. D. G. M.; Ciência e Tecnologia de Alimentos 2007, 27, 391.

117. Oliveira, R.C.; Bando, E.; Machinski Jr, M.; Acta Sci. Health Science 2007, 29, 59 .
118. Spisso, B. F.; Pereira, M. U.; Ferreira, R. G.; Monteiro, M. A.; Costa, R. P.; Cruz, T. A.; Nobrega, A. W.; Food Addit. Contam., Part B 2010, 3, 212.

119. Siqueira, S. R. R.; Donato, J. L.; Nucci, G.; Reyes, F. G. R.; J. Sep. Sci. 2009, 32, 4012.

120. Bilandzi, N.; Kolanovi, B.S.; Varenina, I.; Scortichini, G.; Annunziata, L. A.; Brstilo, M.; Rudan, N.; Food Control 2011, 22, 1941.

121. Chéneau, E. D.; Bessiral, M.; Roudaut, B.; Verdon, E.; Sanders, P.; J. Chromatogr. A 2009, 1216, 8149.

122. Capriotti, A. L.; Cavaliere, C.; Piovesana, S.; Samperi, R.; Laganà, A.; J. Chromatogr. A 2012, 1268, 84

123. Liu, Y.; Yang, H.; Yang, S.; Hu, Q.; Cheng, H.; Liu, H.; Qiu, Y.; J. Chromatogr. B 2013, 917, 11.

124. Xie, K.; Jia, L.; Yao, Y.; Xu, D.; Chen, S.; Xie, X.; Pei, Y.; Bao, W.; Daí, G.; Wang, J.; Liu, Z.; J. Chromatogr. B 2011, 879, 2351.

125. Herranz, S.; Bondi, M. C. M; Marazuela, M. D.; J. Chromatogr. A 2007, 1140,63

126. Bogialli, S.; D’Ascenzo, G.; Di Corcia, A.; Laganà, A.; Tramontana, G.; J. Chromatogr. A 2009, 1216, 794.

127. Bogialli, S.; Ciampanella, C.; Curini, R.; Di Corcia, A.; Laganà, A.; J. Chromatogr. A 2009, 1216, 6810. 